\title{
Focusing the customer through smart services: a literature review
}

\author{
Sonja Dreyer ${ }^{1}$ D $\cdot$ Daniel Olivotti $^{1} \cdot$ Benedikt Lebek $^{2} \cdot$ Michael H. Breitner $^{1}$
}

Received: 30 March 2017 / Accepted: 3 January 2019 / Published online: 9 February 2019

(C) The Author(s) 2019

\begin{abstract}
Smart services serve customers and their individual, continuously changing needs; information and communications technology enables such services. The interactions between customers and service providers form the basis for co-created value. A growing interest in smart services has been reported in the literature in recent years. However, a categorization of the literature and relevant research fields is still missing. This article presents a structured literature search in which 109 relevant publications were identified. The publications are clustered in 13 topics and across five phases of the lifecycle of a smart service. The status quo is analyzed, and a heat map is created that graphically shows the research intensity in various dimensions. The results show that there is diverse knowledge related to the various topics associated with smart services. One finding suggests that economic aspects such as new business models or pricing strategies are rarely considered in the literature. Additionally, the customer plays a minor role in IS publications. Machine learning and knowledge management are identified as promising fields that should be the focus of further research and practical applications. Concrete ideas for future research are presented and discussed and will contribute to academic knowledge. Addressing the identified research gaps can help practitioners successfully provide smart services.
\end{abstract}

Keywords Smart services $\cdot$ Value co-creation $\cdot$ Literature review $\cdot$ Status quo analysis $\cdot$ Future research agenda

JEL classification $\mathrm{L} 80 \cdot \mathrm{L} 86$

\section{Introduction}

Increasing digitalization and the emergence of the Internet of Things have fostered growing interest in smart services in

This article is part of the Topical Collection on Smart Services: The move to customer-orientation

Responsible Editor: Rainer Alt

Sonja Dreyer

dreyer@iwi.uni-hannover.de

Daniel Olivotti

olivotti@iwi.uni-hannover.de

Benedikt Lebek

lebek.benedikt@bhn-services.com

Michael H. Breitner

breitner@iwi.uni-hannover.de

1 Information Systems Institute, Leibniz Universität Hannover, Koenigsworther Platz 1, 30167 Hannover, Germany

2 BHN Dienstleistungs GmbH \& Co. KG, Hans-Lenze-Strasse 1, 31855 Aerzen, Germany recent years (Georgakopoulos and Jayaraman 2016). Smart services are characterized by the fact that the service provider and the customer interact to create value. This process is called value co-creation (Gavrilova and Kokoulina 2015) and enables service providers to continuously adjust to a customer's individual and constantly changing needs (Massink et al. 2010). Customers are supported, and new business models are realized via smart services.

The number of publications that have focused on smart services has greatly increased in recent years. Although these publications have answered many relevant research questions, none have yet articulated a systematic and comprehensive research agenda for smart services. Systematic insights in different topics help to provide a broader view on the subject (Kamp et al. 2016). Therefore, the objective of the article is to present a holistic overview of past research and opportunities for further research in the field of smart services.

The presented literature review clusters existing publications related to smart services based on topics and lifecycle phases. Both in theory and practice, the lifecycle concept is adopted to describe a product or service from the design to the continual improvement (e.g., Fischbach et al. 2013; Wiesner et al. 2015). It helps to organize the complex structure of a 
product or a service and makes it more transparent. In this article, this approach is also applied to smart services, since the lifecycle indicates that they are dynamic and constantly refined. How to involve customers to meet the requirements and to provide successful smart services varies in the different phases. Only passing the lifecycle together with the customers enables value co-creation. By investigating existing research and future research opportunities in the context of a smart service lifecycle, a new viewpoint is taken that is not yet considered in literature. It enables to consciously view a specific step from the strategy development to the continual improvement. Through the lifecycle, not only a topic-centered focus is considered in the present review but also an organizational perspective. It enables to identify phases that are unexplored.

The research intensity in different fields is discussed. It aims at getting an overview of smart service research. Past results are presented briefly, and research gaps are identified. For example, the customer is generally accepted as an essential component of successful smart services but has rarely been the focus of research. Additionally, few viewpoints on operating smart services exist.

Investigating concrete starting points for further research will advance the understanding of smart services in the IS literature. For example, some possible future contributions are identifying appropriate technology and necessary data streams. In practice, knowledge gained through theoretical research can be used to introduce new perspectives on smart services. For practitioners, designing, realizing and maintaining them is a key need (Kamp et al. 2016). Because such services are a relatively new development, best practice approaches have not been well defined. Theoretical investigations can help practitioners to provide smart services successfully.

To present a comprehensive literature review including suggestions for further research opportunities, the following research questions are investigated:

RQ 1: How does academic literature conceptually approach smart services along the smart service lifecycle?

RQ 2: Which research gaps and related further research opportunities can be derived from prior research on smart services?

Based on the approach presented by Webster and Watson (2002), a literature review is conducted by searching through academic databases using a set of predefined search terms. This review includes a forward and backward search, as well as a search using the Tool for Semantic Indexing and Similarity Queries (TSISQ), a literature tool presented by Koukal et al. (2014). In total, 109 publications were found to be relevant and are included in the literature review. After assigning each publication to at least one of the smart service lifecycle phases, an analysis of several topics is performed. Five lifecycle phases, in addition to the investigated topics, are used to develop a heat map. The heat map shows the research intensity for each combination of topics and lifecycle phases. Selected areas of the heat map are analyzed and discussed. Based on the findings, directions for further research are presented.

The remainder of this article is structured as follows: a definition of smart services is derived, and the smart service lifecycle is presented. Next, the research design is explained, and the results of the literature review are presented. Finally, results are discussed and directions for further research are developed. The article concludes with limitations and conclusions.

\section{Smart services and a smart service lifecycle}

Although there is little controversy regarding how to define smart services, various authors emphasize different aspects and characteristics of the fundamental topics. Smart services co-create value by the customers and providers via connected systems and machine intelligence (Gavrilova and Kokoulina 2015). Interaction between customer and provider is necessary, in addition to the service offered by the technology itself (Baldoni et al. 2010; Wünderlich et al. 2012; Demirkan et al. 2015). Through collaboration the service provider knows the current needs and thus can adapt the smart service constantly. Lee et al. (2012) suggested that value co-creation does not require direct input from a customer because functionalities should be provided in a convenient way. Nevertheless, the present article indicates that the customer and the environment are involved and form an important part in all phases from a strategic development to the improvement of operational smart services. This interaction can be direct, e.g. in form of feedback, or indirect, e.g. by providing information. By considering individual needs it is possible to improve and simplify the customers' tasks and processes, both in the business-tobusiness (B2B) and the business-to-consumer (B2C) sector (Massink et al. 2010). Smart services are quality-based services, thus services in which the quality of processes plays a decisive role for economic success (Gerke and Tamm 2009).

Smart services are strictly based on field intelligence (Allmendinger and Lombreglia 2005). Field intelligence refers to the concept that connected systems and devices pave the way to intelligence that is higher than the intelligence of the individual parts. It is enabled by context information and high dynamics (Oh et al. 2010; Byun and Park 2011). Support from technology such as information and communications technology, as well as the ability to react to an individual's context and its changes make up "smart" service (Calza et al. 2015). Intelligent sensors (i.e. sensors that not only collect data, but also prepare and preprocess them) are often used to 
determine the current contexts (Byun and Park 2011; Delfanti et al. 2015), combined with continuous communication and feedback (Wünderlich et al. 2015). Information from several sources, including technology, the environment and social contexts (Alahmadi and Qureshi 2015; Lee et al. 2012) is collected and then presented, or suggestions are made via data analysis (Kynsilehto and Olsson 2012).

Based on the aspects named in the literature, the following definition of smart services is derived, forming the basis for this article:

Smart services are individual, highly dynamic and quality-based service solutions that are convenient for the customer, realized with field intelligence and analyses of technology, environment and social context data (partially in real-time), resulting in co-creating value between the customer and the provider in all phases from the strategic development to the improvement of a smart service.

The definition contains the necessary attributes of a smart service from the article's point of view. Individual customer needs are not mentioned as precondition because they must be considered to be able to offer individual smart services. Additionally, customer needs often are the result of data analyses what forms part of the definition. Information and communications technology is not named explicitly because it is necessary for field intelligence and analyses, what forms part of the definition. The reaction to the individual's context is represented by naming that smart services are highly dynamic as well as individual. Intelligent sensors are only one possibility to receive data which is why it is not mentioned in the general definition. The same applies to the feedback of the customer. For what the collected data and information from different sources are used depends on the specific smart service and cannot be answered generally. As business and private customers are the only two possible target groups, it is assumed to be not a necessary part of the definition.

Predictive maintenance for production machines is an example for a smart service. Depending on the machines, production processes, current production planning and further factors, maintenance activities are planned and continually adapted. For example, mathematical models and artificial intelligence in connection with data in real-time contribute to an individual and dynamic solution. Constant exchange of knowledge and information enables the development as well as continual adaption and optimization of the applied predictive maintenance service. Additionally, feedback of the customer enables to adapt the scope of service. Thinking of predictive maintenance, after a while the customer might want that the provider does not only carry out predictive maintenance activities, but also the spare parts supply. The service provider orders spare parts when they are required, thereby fixed capital is reduced. Considering this aspect further, another form of collaboration between customer and service provider is imaginable; the customer can become a coproducer. When small spare parts, e.g. gearwheels, are needed, they could be printed in 3D by the customer itself. Thereby, machine downtimes resulting from delivery times are reduced. Detailed data and information that are required for the 3D print are supplied by the service provider.

For physical products, it is common to think in terms of their lifecycle, from the planning and development to the improvement stages. Services have a similar lifecycle (Fischbach et al. 2013). Several publications describe services in a lifecycle using a model that has phases progressing from idea to improvement (e.g., Niemann et al. 2009; Wiesner et al. 2015). Smart services are also subject to a lifecycle that ranges from strategic development to service improvement. In this article, it is referred to the basic service lifecycle defined in the Information Technology Infrastructure Library (ITIL) framework because it contains and clearly defines the phases of a service lifecycle. The sub-processes described in the ITIL lifecycle are not considered. This framework is widely accepted and contains best practice approaches, from both the public and private sectors (Cater-Steel et al. 2011). It is suitable for quality-based services that use information technology (Gerke and Tamm 2009). These characteristics apply to smart services, which is why the framework is considered adequate.

The service lifecycle of the current version from 2011 consists of five phases. In the first phase, the process objective is defined. Based on customer requirements, a service strategy is developed, and the necessary capabilities are defined. A more theoretical view of smart services discusses business alignment due to this kind of services. The second phase, namely service design, uses a predefined strategy to design services. The phase considers all articles that propose new smart services as a whole, i.e. infrastructures, service platforms, or related necessary aids. Deployment of the designed services is covered in the service transition phase, describing the way in which a new or changed smart service is implemented. Descriptions of a concrete implementation within a use case are included. The fourth phase is the service operation phase; this phase contains failure management, maintenance, and the execution of tasks and processes. Publications describing challenges and requirements during the use phase of a service are included. The final phase of the service lifecycle is continual service improvement. Learning from past successes and failures is a key component of this phase. This phase also describes how to continually adapt a service, use its pertinent data and information, and involve the customers. Figure 1 illustrates the described service lifecycle transferred to smart services. 


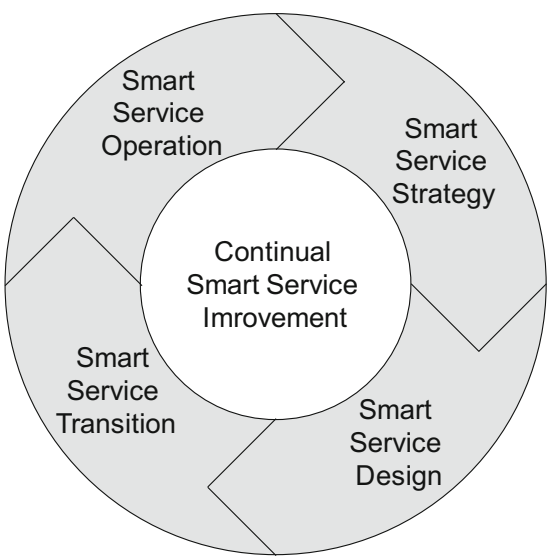

Fig. 1 Smart service lifecycle following the ITIL framework

\section{Research design}

The research design for this study includes two components: identifying relevant literature and analyzing it. The first part describes how the comprehensive and broad literature search is conducted. The second part presents how the identified literature is analyzed. The research design enables to review existing contributions to obtain a comprehensive overview of the status quo.

\section{Identifying relevant literature}

To find relevant literature that focuses on smart services, a systematic search was performed. To ensure a structured and broad overview, the approach by Webster and Watson (2002) was chosen as the underlying methodology. According to Vom Brocke et al. (2009), validity and reliability are essential components of a rigorous literature search. In general, validity is defined as the degree of accuracy, and, for a literature review, the validity is regarded as the degree to which all publications relevant to a topic are discovered (Vom Brocke et al. 2009). For this study, the validity of the literature search was considered by examining the selected databases, the predefined search terms, the performance of forward and backward searches, and the use of the TSISQ (Koukal et al. 2014). The TSISQ uses the concept of latent semantic indexing and is an extension of conventional term-matching methods. Reliability is generally understood to be the formal precision of a scientific study. In the case of a literature search, reliability is the replicability of the search process; thus, it is necessary to comprehensively document the search process (Vom Brocke et al. 2009).

Searches were carried out in the following eight databases: ACM, AISeL, Emerald Insight, IEEEXplore, InformsOnline, JSTOR, Science Direct, and SpringerLink. These databases provide articles from the most important outlets in the ISR field and yield different rankings, such as the VHBJOURQUAL3 ranking. A search was not only carried out for the term "smart service" but also for digital and electronic services; The latter two terms have sometimes been used as synonyms for smart services, especially in earlier publications. To summarize, the three predefined search terms were as follows:

- "smart service" OR "smart services"

- "digital service" OR "digital services"

- "electronic service" OR "electronic services" OR "e-service" OR "e-services"

A search was performed in the listed databases to determine whether a publication contained at least one of the search terms in the title or abstract. For SpringerLink and InformsOnline, it was not possible to specify the criteria in the search field; therefore, a full-text search was conducted on these databases. There were 25,056 hits in total from all the databases.

Inclusion and exclusion criteria were defined to identify the most relevant articles. Publications that were non-academic articles or not peer-reviewed were filtered out. However, to be sure of achieving a broad literature review, the search was not limited to high-ranking journals and conferences. According to Webster and Watson (2002), a topic-centric view of the literature is much more valuable than a view limited to a few top journals. Articles that were not written in English were excluded, which is why only English search terms were used to identify relevant literature. It was assumed that potentially relevant articles in the field of smart services would be in English because most researchers write in English, aiming to address a broad target group. To avoid regional overrepresentation of research in the formal analysis, articles in other languages were excluded. This choice also helped avoid regional bias based on differences in research topics. After implementing the named inclusion and exclusion criteria, 10,012 potentially relevant hits remained. In this literature review smart services are viewed from an ISR perspective. Articles in different disciplines such as history or art were excluded. This criterion was applied by using the filters whenever possible while searching the different databases and disciplines. A publication by Bianchi (2015), which includes a discussion of the roles of risks and trust in art exchanges, is an example of an article that was not from the ISR field and thus excluded. Additionally, articles that only used the terms smart/ digital/electronic service, without subsequently focusing on these topics, were not considered. One example is a technical analysis and presentation of strategies for network scenarios (Sohn and Gwak 2016).

Most of the articles were found using second and third search terms; that is, they contained the terms "digital" or "electronic", but not "smart". The definition of smart services presented earlier was used to determine whether an article was using the terms "digital service" or "electronic service" as a 
synonym for smart services. Implementing this criterion led to a large reduction in potentially relevant articles, because most of the articles that used the second and third search terms did not consider "smart" services in accordance with the definition presented in this article. Appendix Table 4 shows the number of hits and their reduction for each search term in the different databases. If it was not possible to decide whether the terms used in an article complied with the definition of smart services considered in this article, the full text was examined. An article by Mecella and Pernici (2001) is an example of a hit using the search term "electronic service" that was eventually excluded. They define electronic services as open, developed for interaction in an organization and between organizations and as easily composable. Using this definition, electronic services are not necessarily based on context information or data analytics.

Following the search described above, both a backward and a forward search were conducted (Webster and Watson 2002). For the backward search step, the citations of the articles were screened manually for additional relevant literature. Google Scholar was used for the forward search to find articles that cited the identified literature, resulting in seven additional articles. Finally, the literature tool TSISQ (Koukal et al. 2014) was used to enhance the keyword-based search via latent semantic indexing. The tool compares unstructured texts and identifies semantically similar texts in a database. The database contains IS literature from the "AIS basket of eight" and other IS conferences and led to the identification of two further articles. In total, 109 articles were considered in the literature review. Figure 2 illustrates the literature search process.

\section{Analyzing the identified literature}

In the second phase of the literature review an analysis of the identified articles was conducted, involving the following steps: identifying relevant aspects and issues, categorizing them and discussing the highlights and results. First, a formal exploration of the 109 articles was conducted. The years of publication were examined to identify a possible trend. The identified industries used as context were also determined. Next, the articles were analyzed thematically.
The smart service lifecycle explained in section two was used to identify the phases covered by each article. During analysis, it was found that considering the service lifecycle is helpful for organizing the relevant publications. Associating research with a specific lifecycle phase enabled to draw more concrete conclusions and to better understand the opportunities and challenges. For each article in the literature review, it was determined which phases of the smart service lifecycle were covered. The service lifecycle is also relevant in practice. Niemann et al. (2009) indicated that a given topic must be examined at multiple points in the smart service process. All existing publications focus on specific lifecycle phases but do not consider the entire lifecycle. The considered topics were also analyzed. In the different phases it is focused on different topics. As not all articles identified can form part of the findings section, publications are selected that, in total, represent the diversity of research results.

Based on the categorizations, a heat map was created to show the number of articles published for each topic and lifecycle phase. The heat map formed the basis for a discussion of important research fields. As a result, research gaps were identified that form promising areas for further research.

\section{Findings}

Based on the 109 identified publications, both a formal and a content analysis were conducted. The formal analysis provides a first insight into the publications covering smart services. The publications were then categorized based on the phases of the smart service lifecycle that they covered and the topics they considered. This forms the basis for the subsequently developed heat map and the discussion of research gaps.

\section{Categorization of the literature}

The issue of smart services was first mentioned in the literature in 2003 (Fig. 3a). Initially, the term "electronic service" emerged for individual and interactive services. One year later, the term "smart service" appeared for the first time in the literature and finally became widely established in 2010 . For

Fig. 2 Literature search process

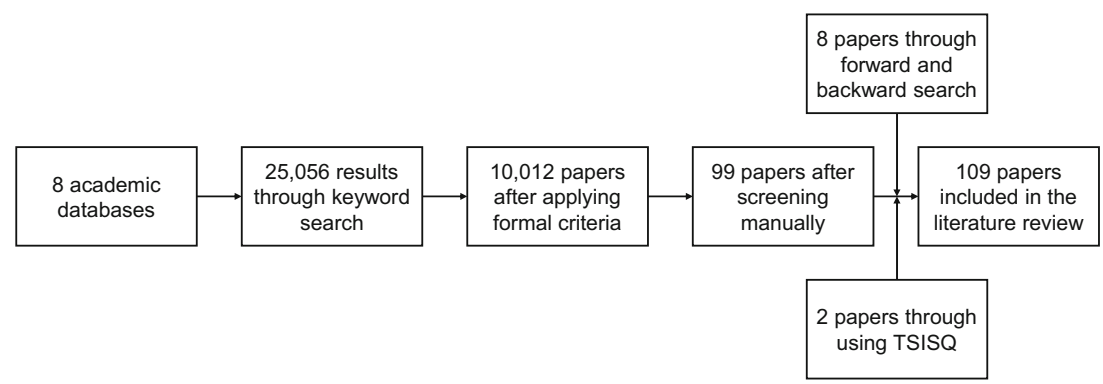


Fig. 3 a Years of publication. b Research contexts

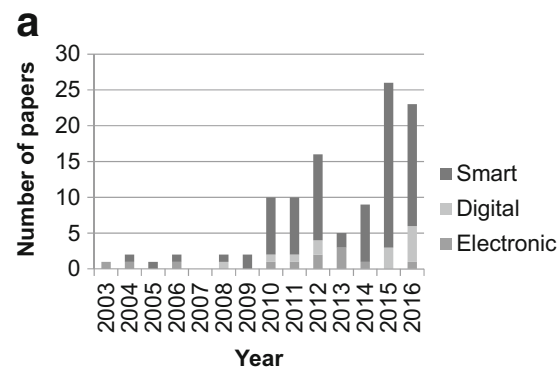

b

\begin{tabular}{ll}
\hline Industry & Number of papers \\
\hline \hline General & 34 \\
Manufacturing & 19 \\
Health & 17 \\
City & 13 \\
Home & 11 \\
Website/App & 6 \\
Government & 5 \\
Grid & 5 \\
Tourism & 3 \\
Robotic & 3 \\
Others & 5
\end{tabular}

three years, the interest was constant or growing. Although research in this field declined temporarily, it reached a new peak during the past years.

There is no outlet that concentrates publications dealing with smart services. Considering the outlets that researchers chose more than once (Appendix Table 5), conferences are the most common. The research context is also broad. Smart services are most often discussed in literature in the fields of manufacturing and healthcare. The topics of smart cities and smart homes also occur frequently. General approaches that do not specialize in a specific industry are also common (Fig. 3b). An overview of the industries considered by each publication is presented in Appendix Table 6. Details on the origins of the first authors and the target groups can be found in Appendix Fig. 5. The identified publications were categorized according to the phase of the smart service lifecycle that they represent (Table 1). The design and the transition phases were the most frequently considered parts of the service lifecycle. To date, little research has been done in the field of smart service operation.

After assigning the publications to the relevant phases of the service lifecycle, the publications were categorized according to their focus. These topics were not predefined but were derived continuously throughout the literature review. In total, 13 topics were identified (Table 2), and each article was reviewed to determine whether it covered each topic. Each article focuses on at least one of the key topics.

\section{Smart service strategy}

In total, 25 articles deal with the strategic level of smart services; this number is relatively low compared to the later phases of the smart service lifecycle. Discussions about the most suitable technologies and how to include them in the strategy occurred in eleven articles (e.g., Ferretti and D'Angelo 2016; Perera et al. 2014). Six different risk types in the context of technology-based service innovations, namely privacy, functional, financial, psychological, temporal and social risks revealed challenges (Paluch and Wünderlich 2016). Interviews with both providers and customers enabled to identify the most important risks. From a provider's perspective, it is privacy risks while functional risks are named most frequently by customers.
The eight articles (e.g., Smith et al. 2016; Tien 2012) that considered data during the strategy phase suggested that data represent a key factor in providing smart services. Using remote maintenance services as an example, real-time data are necessary to make such services possible. Looking at technologies, they should support data collection (Holgado and Macchi 2014).

The context in which a smart service is provided is a key ingredient for satisfying customer demands (Lee et al. 2012). The customer should be involved to find a strategy for satisfying individual needs (Spottke et al. 2016; Wang et al. 2012). A certain level of service quality contributes to customer satisfaction. The perception of service quality strongly impacts the probability that a service will be used again (Zo 2003). This is especially true when multiple services are interconnected (Wang et al. 2012).

\section{Smart service design}

In total, 59 articles examined the smart service design phase, covering a set of diverse topics. Service design should always be context-aware (Weijie et al. 2012). A design approach showed how to use industrial equipment for smart services (Priller et al. 2014). Considering existing production lines, the approach enables to make equipment smart to integrate it into the smart service world. A similar approach resulted in a platform as basis for smart mobile health services (Alti et al. 2015).

In contrast to the strategic phase, standardization, security and privacy concerns were frequently investigated. The dominant conclusion regarding standardization was that standards are necessary to combine and extend smart services and apply them to individual customer requirements. Open standards are necessary when designing new services (Kryvinska et al. 2008). Such standards enable a rapid and cost-effective development (Mihaylov et al. 2015). A model-driven approach that refers to several standards and contains different combined methods enabled the design of service systems (De Oliveira and Silva 2015). A case study showed applicability in practice.

A total of 14 articles (e.g., Gretzel et al. 2015; Roduner and Langheinrich 2010) highlighted the importance of security and privacy issues. Privacy is a fundamental challenge with 
Table 1 Publications categorized by the covered phases of the service lifecycle

\begin{tabular}{|c|c|c|c|c|}
\hline Author & Service strategy & Service design & Service transition & Service operation \\
\hline
\end{tabular}

Abbate et al. (2015)

Abdellatif et al. (2013)

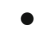

Adeleke and AbdulRahman (2011)

Al Nuaimi et al. (2015)

Allmendinger and Lombreglia (2005)

Alti et al. (2015)

Anthopoulos and Fitsilis (2014)

Anthopoulos et al. (2016)

Anttiroiko et al. (2014)

Baldoni et al. (2010)

Barile and Polese (2010)

Batubara (2015)

Bedogni et al. (2013)

Berna-Martinez et al. (2006)

Böcker et al. (2010)

Brotman et al. (2015)

Buchanan and McMenemy (2012)

Buettner (2016)

Byun and Park (2011)

Calza et al. (2015)

Cardozo and Clarke (2015)

Cellary (2013)

Chatterjee and Armentano (2015)

Chen et al. (2012)

Chu and Lin (2011)

Ciortea et al. (2016)

Dawid et al. (2016)

De Oliveira and Silva (2015)

Delfanti et al. (2015)

Domingues et al. (2010)

Fan et al. (2012)

Fan et al. (2016)

Ferretti et al. (2016)

Ferretti and D'Angelo (2016)

Georgakopoulos and Jayaraman (2016)

Geum et al. (2016)

Gillig and Sailer (2012)

Gretzel et al. (2015)

Hamdan et al. (2012)

He et al. (2012)

Holgado and Macchi (2014)

Hong et al. (2014)

Jerald et al. (2016)

Kamp et al. (2016)

Kennedy and Keskin (2016)

Keskin and Kennedy (2015)

Kim et al. (2015)

Knote and Blohm (2016)

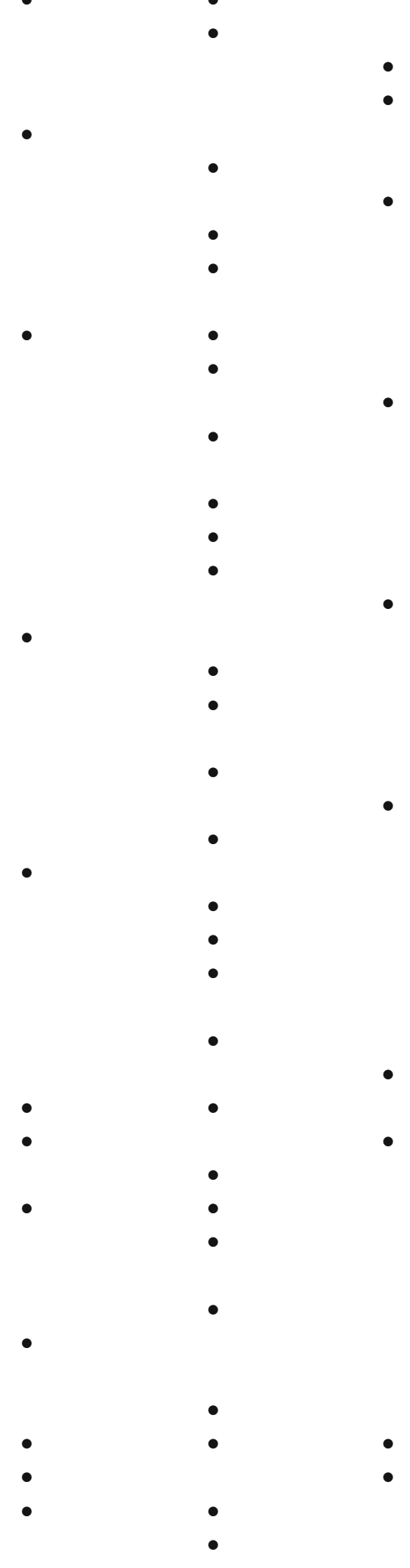


Table 1 (continued)

\begin{tabular}{|c|c|c|c|c|c|}
\hline Author & Service strategy & Service design & Service transition & Service operation & $\begin{array}{l}\text { Continual service } \\
\text { improvement }\end{array}$ \\
\hline
\end{tabular}

Kölmel and Bulander (2015)

Korzun et al. (2015)

Kryvinska et al. (2008)

Kuebel and Zarnekow (2015)

Kwak et al. (2014)

Kynsilehto and Olsson (2011)

Kynsilehto and Olsson (2012)

Lê Tuán et al. (2012)

Lebedev et al. (2016)

Lee et al. (2010)

Lee et al. (2012)

Lee et al. (2015)

Lee et al. (2016)

Lesjak et al. (2014)

Lesjak et al. (2015)

Li et al. (2015)

Ma et al. (2010)

Maleshkova et al. (2016)

Martin et al. (2004)

Massink et al. (2010)

Mathes et al. (2009)

Mihaylov et al. (2015)

Mihovska et al. (2015)

Mo et al. (2010)

Moawad et al. (2015)

Mukudu et al. (2016)

Nakajima et al. (2012)

Oh et al. (2010)

Oslislo et al. (2011)

Paluch and Wünderlich (2016)

Pao et al. (2011)

Perera et al. (2014)

Pistofidis and Emmanouilidis (2012)

Priller et al. (2014)

Ren et al. (2014)

Roduner and Langheinrich (2010)

Sakakibara et al. (2016)

Seeliger et al. (2015)

Singhai and Faizan (2016)

Smirnov et al. (2015)

Smith et al. (2016)

Son et al. (2011)

Spottke et al. (2016)

Strüker and Kerschbaum (2012)

Tantatsanawong et al. (2011)

Theocharis and Tsihrintzis (2013)

Tianyong et al. (2006)

Tien (2012) 
Table 1 (continued)

\begin{tabular}{|c|c|c|c|c|c|}
\hline Author & Service strategy & Service design & Service transition & Service operation & $\begin{array}{l}\text { Continual service } \\
\text { improvement }\end{array}$ \\
\hline Wang et al. (2011) & & & & & $\bullet$ \\
\hline Wang et al. (2012) & $\bullet$ & $\bullet$ & & & \\
\hline Weijie et al. (2012) & & $\bullet$ & & & \\
\hline Westwood and Cazier (2016) & & & $\bullet$ & & \\
\hline Williams et al. (2008) & $\bullet$ & $\bullet$ & & & \\
\hline Wünderlich et al. (2012) & & $\bullet$ & & & \\
\hline Wünderlich et al. (2015) & $\bullet$ & $\bullet$ & & & \\
\hline Yachir et al. (2009) & & $\bullet$ & & $\bullet$ & $\bullet$ \\
\hline Yang et al. (2015) & & $\bullet$ & $\bullet$ & & \\
\hline Yong and Hiu-ying (2013) & & $\bullet$ & & & \\
\hline Yu (2004) & & & & & $\bullet$ \\
\hline Zhang and Qi (2011) & & & $\bullet$ & & \\
\hline Zo (2003) & $\bullet$ & & $\bullet$ & & \\
\hline Total number of articles & 25 & 59 & 40 & 5 & 19 \\
\hline
\end{tabular}

Table 2 Key topics in the literature and aspects focused on in the context of smart services

\begin{tabular}{|c|c|}
\hline Topic & Focus on \\
\hline (Big) Data & $\begin{array}{l}\text { - Data analysis } \\
\text { - Importance of data for smart services }\end{array}$ \\
\hline Business models & $\begin{array}{l}\text { - General approaches for business model } \\
\text { design } \\
\text { - Concrete business models }\end{array}$ \\
\hline Customer involvement & $\begin{array}{l}\text { - Role of customer } \\
\text { - Customer requirements }\end{array}$ \\
\hline Knowledge management & $\begin{array}{l}\text { - Technologies for information processing } \\
\text { - Means of showing or applying information }\end{array}$ \\
\hline Machine learning & $\begin{array}{l}\text { - Approaches for specific functionalities } \\
\text { - General approaches for using machine } \\
\text { learning for smart services }\end{array}$ \\
\hline Pricing & $\begin{array}{l}\text { - Pricing strategies } \\
\text { - Analysis of different pricing models }\end{array}$ \\
\hline Security/privacy & $\begin{array}{l}\text { - Role concepts and user management } \\
\text { - Security and privacy concerns }\end{array}$ \\
\hline Service quality & $\begin{array}{l}\text { - Measuring the quality of smart services } \\
\text { - Aspects of smart service quality }\end{array}$ \\
\hline Standardization & $\begin{array}{l}\text { - Of data and information } \\
\text { - Of technological aspects }\end{array}$ \\
\hline Technology & $\begin{array}{l}\text { - Technological perspective on smart services } \\
\text { - Discussions of appropriate technology } \\
\text { - Presentation and evaluation of infrastructure }\end{array}$ \\
\hline Trends & - Future trends of smart services \\
\hline Usage behavior & $\begin{array}{l}\text { - Measuring and analyzing usage behavior } \\
\text { - Perspectives for applying knowledge of } \\
\text { usage behavior }\end{array}$ \\
\hline User interface & $\begin{array}{l}\text { - Examples of user interfaces } \\
\text { - Theoretical contributions on how a user } \\
\text { interface supports smart services }\end{array}$ \\
\hline
\end{tabular}

respect to the concept of "smartness" (Cellary 2013). In the field of smart governance, the possibility of identifying any person at any time causes privacy problems. Therefore, rules and regulations regarding security and privacy are required for a successful smart service. Broadly, security is the primary concern regarding the Internet of Things technology (Keskin and Kennedy 2015). Therefore, it must be considered during the service design phase. The implementation of a maintained and frequently updated knowledge management helps to quantify security and privacy risks, e.g., through providing lists of risks for different situations or technologies (Moawad et al. 2015).

Eleven articles (e.g., Buchanan and McMenemy 2012; Yong and Hui-ying 2013) investigated how to involve the customer during the smart service design process. The importance of customer involvement is justified by the fact that value should be co-created (Wünderlich et al. 2012). A framework for user involvement helps to optimize the service design process (Gillig and Sailer 2012). A study enabled to develop the framework and shows that the customers must be analyzed from the beginning, e.g. regarding their role, activities and environment. For example, machine learning techniques are helpful to analyze the customers and to identify preferences (Abdellatif et al. 2013).

Although business models are changing through the Internet of Things (Keskin and Kennedy 2015), it is rarely a subject of discussion when investigating smart services. Pricing is only named one time as a fundamental design dimension of a comprehensive business model (Williams et al. 2008). 


\section{Smart service transition}

In total, 40 publications focused on smart service transition. As in other lifecycle phases, technologies and big data received the most attention in the transition phase. Technology-based services generally have great potential (Paluch and Wünderlich 2016). Especially context-aware tools enable smart services and help to adapt them to individual customer needs (Pistofidis and Emmanouilidis 2012). The implementation of a robotic system for smart home-care services illustrated that openness and flexibility is a key for successful smart service technology (Ma et al. 2010).

The use of large datasets, e.g. in form of real-time data, provides great potential regarding the identification of individual customer needs (Lê Tuán et al. 2012). But when introducing a service based on big data, several challenges and potential problems must be carefully investigated (Al Nuaimi et al. 2015). It must be ensured that the foundations are laid to be able to transform different types of data into storable datasets ( $\mathrm{Li}$ et al. 2015). Dynamic environments require robustness when collecting, transforming and storing big data ( $\mathrm{Al}$ Nuaimi et al. 2015).

The user interface plays a central role in the academic literature and was mentioned six times (e.g., Mukudu et al. 2016; Oh et al. 2010) in discussions of the smart service transition phase. All researchers that dealt with this topic agreed that an intuitively operable user interface is a key component for interaction with the customer. An interactive user interface improves efficiency and simplifies smart service transition (Pao et al. 2011). It is important to understand both usage behavior and a customer's preferences and needs to implement a suitable user interface (Seeliger et al. 2015).

Knowledge management only occurred twice (Chu and Lin 2011; Li et al. 2015) in this phase as a topic of discussion. Knowledge is a valuable asset when offering smart services and improves the efficiency of communication and coordination (Chu and Lin 2011). Smart services are knowledgeintensive and require consistent knowledge management (Chu and Lin 2011; Li et al. 2015); this management includes collecting, packaging, distributing and reusing knowledge (Ferneley et al. 2002). That is why a knowledge management portal is a precondition to create and realize innovative services. The idea is to use knowledge management to implement a learning culture within an organization. A medical knowledge recommendation service for patients functions as starting point for designing an information framework to enable knowledge management in the health sector ( $\mathrm{Li}$ et al. 2015). A prototype shows how to implement such a framework in practice. Connected to knowledge management, little attention has been paid to machine learning techniques. Kamp et al. (2016) are the only authors who recommended conducting data analyses using machine learning techniques.
During the service transition phase, machine learning can help to ensure the quality of the processes.

\section{Smart service operation}

Only five articles dealt with the service operation phase, which received the least amount of attention in the literature. The three articles (Chatterjee and Armentano 2015; Lee et al. 2010; Yachir et al. 2009) concerned with technologies agreed that technology which operates smoothly is essential for individual and dynamic smart services. Taking the healthcare sector as an example, a system for electronic health services that bases on the Internet of Things contributes to smooth operation (Chatterjee and Armentano 2015). Technology that is used for monitoring especially is important to guarantee the functionality of a smart service (Lee et al. 2010). A real-time monitoring system enables to process sensor data during service operation (Lee et al. 2010). Looking at technologies for data analyses, effective fault diagnosis in wireless sensor networks is important for a successful service operation (Hamdan et al. 2012). Abstraction of functionalities for heterogeneous devices is required in order to support interoperability for concurrency management and failure detection in whole systems (Baldoni et al. 2010). Scalability of large data handling during an operation based on the number of connected devices is necessary (Lee et al. 2010). To compose different smart services, several parameters must be considered. One of the most important parameters is the quality of services (Yachir et al. 2009).

\section{Continual smart service improvement}

In total, 19 articles address the requirement to continually improve smart services. Seven of these articles (e.g., Kwak et al. 2014; Yu 2004) focused on service quality. In addition to discussing the importance of service quality, recommendations help to understand how it can be determined. For example, a mathematical model can be used to estimate the quality of a service. An algorithm was developed using previously defined preconditions and determines whether these are fulfilled (Yachir et al. 2009). Another approach is the provision of a list of indices. They help to measure service quality based on considerations regarding the service provider, customer, and platform (Hong et al. 2014).

Four articles (e.g., Böcker et al. 2010; Kuebel and Zarnekow 2015) concluded that the usage behavior should be considered when improving smart services. A system should be able to learn from usage behavior (Kynsilehto and Olsson 2011). Knowledge management systems that integrate domain knowledge and human expertise (Wang et al. 2011) enable to detect, analyze and respond to the customer's local environment and the usage behavior (Kynsilehto and Olsson 2011). 


\section{Discussion of research gaps and further research topics}

The discussion of opportunities for further research consists of two parts. First, the research intensity along the different topics and lifecycle phases is summarized to get an overview of the role of smart services in the literature. Second, five specific fields are discussed to provide promising starting points for further research.

\section{Research intensity in the field of smart services}

The results indicate a growing interest in the topic of smart services in the ISR field since 2010. A heat map was created using the 109 articles analyzed in the literature review (Fig. 4). Each article was assigned to at least one area of the heat map, and each area describes a combination of a topic and a lifecycle phase.

The colors in the heat map represent the number of articles in an area. A detailed overview of the publications and their respective areas can be found in Appendix Table 7. As demonstrated by the heat map, research intensity in the different areas is highly variable. In many areas (the cold areas), there is hardly any research. It is necessary to examine whether these are interesting for research, because it is not sensible to look at a specific topic in each lifecycle phase; or whether they are good starting points for further research. In contrast, other areas (hot areas) include many articles. For these areas, the question is whether more research is needed; in other words, whether the area has already been comprehensively explored, or if it is a diverse area where research is still required.

In the following discussion, it is focused on five specific fields that seem to be interesting for discussion (Table 3). Each field integrates several areas that belong together because they address the same topic or lifecycle phase. Both topics and lifecycle phases are considered in the discussion for their potential to provide promising starting points for further research. The fields represent all areas because hot areas, cold areas and areas between these two extremes are considered.

\section{Technologies and (big) data as key enablers in the service design and transition phases}

Most research on smart services was carried out in the fields of technology and big data, particularly in the design and transition phases. In addition to existing research, a classification that can recommend technologies when a specific service is designed would be an important contribution. A discussion of the advantages and challenges of the different technologies would also be an interesting topic for further research. The design phase has a more theoretical perspective, which is why general predictions would support a broader overview of technologies in the field of smart services. Technologies that are necessary for such services can be implemented and are already well covered in the literature. However, previous studies generally discussed a specific application (e.g., Ferretti et al. 2016; Ma et al. 2010). Further analysis of technologies in the transition phase in various contexts would contribute to a broader understanding of smart service implementations.

In the service transition phase, data play an essential role, since smart services are mainly based on data. Real-time data such as sensor data, were emphasized as being interesting for satisfying individual customer needs (Lê Tuán et al. 2012). Specific applications were discussed that are suitable for a specific industry, such as the health sector (e.g., Alti et al. 2015). Prototypes were developed for a specific application and predefined types of customers, such as private end users (e.g., Mukudu et al. 2016). Apart from a specific industry, a
Fig. 4 Summary of research intensity

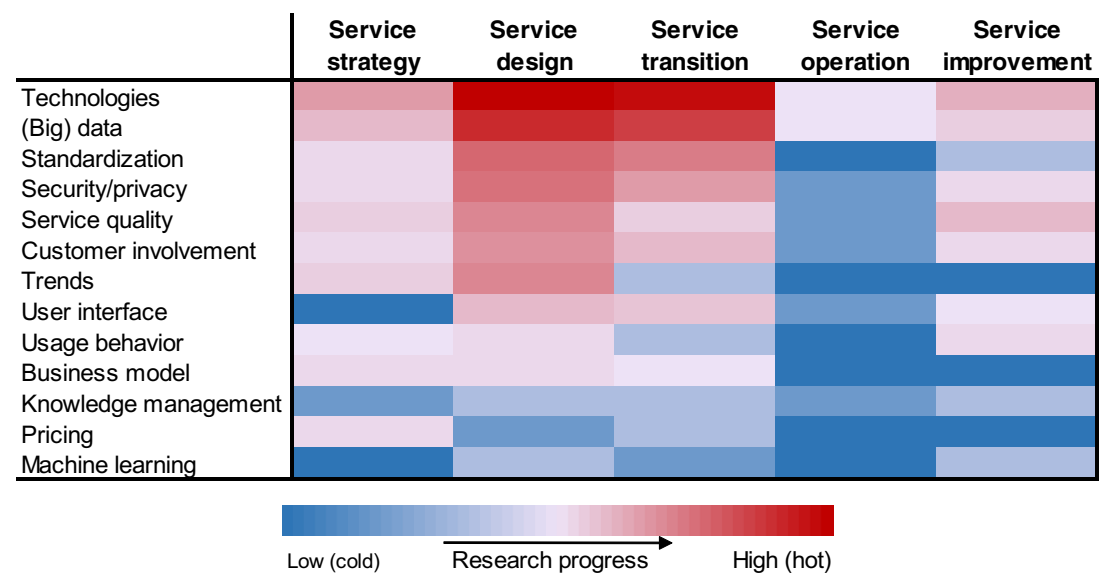


Table 3 Fields of the heat map that are addressed in the discussion

\begin{tabular}{lll}
\hline No. & Topic & Lifecycle phase \\
\hline 1 & Technologies, (big) data & Service design, service transition \\
2 & Costumer involvement, user interface, usage behavior & All phases \\
3 & Knowledge management, machine learning & All phases \\
4 & Business models, pricing & All phases \\
5 & All topics & Service operation \\
\hline
\end{tabular}

structured analysis of the role of data in the design phase is missing. An investigation into the different data types and their importance for different smart services would help to structure the current knowledge of data and data analyses. In the transition phase, special attention is given to concrete examples of the implementation. Taking a more general approach on how to implement smart services on the customer side under consideration of data streams might result in a general framework.

\section{Considering the customer}

Although a characteristic of smart services is that value is co-created via interactions between the service provider and the customer, the role of the customer in the literature has not been as well explored as would be expected. Research has addressed the question of how to involve the customer in the innovation process (e.g., Gillig and Sailer 2012) but customer involvement in the operation and improvement phases is relatively unexamined. While exploratory case studies have already indicated the importance of the customer (e.g., Wang et al. 2012; Spottke et al. 2016), general conclusions across different applications and industries are still missing. A systematic overview of the customer's role across all lifecycle phases of a smart service would help those engaged in the practice to improve their processes. A theoretical framework presenting the role of the customer from a more general perspective would contribute to academic knowledge.

Another aspect regarding the customer's role would be to measure and predict their behavior. Investigating in detail how usage behavior influences smart services in all phases of the lifecycle would provide a better understanding of smart services. It would also be interesting to investigate how usage behavior can be influenced by designing smart services in a specific way. Knowledge about usage behavior would also help to improve customizable user interfaces as the user interface is a critical element for enabling interactions between customer and provider (Tien 2012). One possible approach would be to determine critical success factors related to user interfaces. Systemizing the current knowledge of user interfaces in connection with smart services would enable practitioners to satisfy customer needs.

\section{Knowledge management and machine learning to gain, preserve and use information}

Little attention has been paid to knowledge management and machine learning. Knowledge permits the improvement of the provision of smart services and ensures that past problems and challenges do not persist in the future. Therefore, a knowledge base should be filled, maintained and used (Moawad et al. 2015). A systematic investigation of the role of knowledge management for smart services would contribute to academic research. Studies that compare different approaches would close the gap between theory and practice. Another starting point for further research is the investigation of the extent to which reliable knowledge management can be a success factor for smart services.

Machine learning uses data to continually optimize the services provided. It generally contributes to satisfying individual customer requirements (Abdellatif et al. 2013). The topic of machine learning is diverse and methods suitable for smart services have not yet been established. Researching machine learning in the context of smart services has the potential to uncover new opportunities and may lead to new business concepts. A possible approach is to investigate as to which extend established machine learning methods are suitable for smart services.

\section{Putting smart services into money}

As economic decisions are mainly strategic decisions, business models and pricing strategies are important in the first two phases of the smart service lifecycle. Notably, business models for smart services have rarely been discussed. Business models are changing through smart service systems (Keskin and Kennedy 2015), which is why more attention should be devoted to this topic. One reason for the lack of research into business models for smart services could be the fact that they are 
still under development (Lee et al. 2016). It is difficult to develop a business model without knowing the concrete services that will be provided. An investigation could be carried out to determine whether there are new aspects of a smart service business model that are absent in other business models. This could result in a business model framework for smart services. Although these are relatively general approaches, they help place such services in the context of whole business models.

Pricing strategies have been emphasized and are fundamental for smart service design (Williams et al. 2008). Identifying the best pricing model for a specific smart service is a key for the success. Nevertheless, pricing strategies are rarely discussed in the literature. Depending on the industry concerned, pricing strategies differ. However, the industry is not the only factor that can influence the optimum pricing strategy. The type of customer (i.e. private or business customer) and the corporate strategy also play a role. A systematic investigation of possible additional influencing factors would help to introduce smart services. Based on these factors, it is possible to develop a decision support system that can identify the optimum pricing strategy for a particular service.

\section{Using smart services in practice}

Few academic studies have discussed the phase of smart service operation. Technology and especially sensors have been identified as important tools for smooth operation (Hamdan et al. 2012). Investigating how to run faultless and smooth technical systems for smart services may provide interesting possibilities to connect theory and practice. Researching critical success factors of technologies is interesting both for researchers and smart service providers. A model focusing on the interplay of technologies and further elements such as big data contributes to a comprehensive overview of smart services. Going further in the direction of big data and data collection in real-time, their handling in different application areas in practice may lead to a better understanding of the variety of data and how to process and store them in databases.

The attention that is paid in the smart service operation phase to topics apart from technologies and data is smaller, there are virtually no publications. Some of these cold fields are interesting starting points for further research. An example would be case studies of how security and privacy concerns are considered during the operation phase. The gained knowledge might form the basis for further investigations regarding the role of security and privacy in practice. It might be interesting to find out whether this topic forms a large part when operating a smart service. In turn, this influences the research of security and privacy in the operation phase. The same applies to knowledge management and machine learning. Conducting case studies would provide a first insight in their use in practice. Depending on the findings further research can be conducted, e.g., regarding relevance, challenges and possibilities of machine learning and knowledge management when operating smart services.

Standardization is one example that may be of less interest regarding operation. Generally, standards are determined in the design and transition phases. Although they may be used in the operation phase, this topic has lower potential resulting in new knowledge.

Many topics concerning the customer also contain interesting avenues for further research. Studying usage behavior during the smart service operation phase would be a good basis for subsequent service improvement. Studies on how to track usage behavior could lead to interesting results. Such investigations should not stop at the point of collecting information about the usage behavior, though; appropriately using this information is also an important aspect. Therefore, the operation phase should not be considered in isolation but in connection with the phase of continual improvement.

\section{Limitations}

As a starting point for the literature search, three search terms were predefined; further search terms were not included during the search process. A second search process could be conducted using additional search terms identified during the literature analysis. Similarly, the literature identification process was limited to eight different databases. Although these databases were identified to be the most important ones in the ISR field, searching additional databases could have generated additional results. Additionally, only peer-reviewed articles published in journals or conference proceedings were included in the literature review; whitepapers and book chapters were excluded. Considering these types of publications could have also yielded further results. Next, only one of the search terms contained the word "smart". The definition for smart services was derived based on the literature identified using this search term. Consequently, literature that did not use the words "smart service" but rather "digital service" or "electronic service" was examined to determine whether the use of the terms was consistent with the definition of smart services presented in this article. The decision to include articles resulting from the second and third search terms was based on manual analysis. Considering 
another definition of smart services could have led to other results. Finally, the 13 identified topics were not predefined; they were determined during the literature analysis phase to ensure that all relevant topics were considered. Five fields were selected as starting points for discussion and identification of research fields. The remaining fields would likely also have provided interesting avenues for further research.

\section{Conclusions}

The literature review presented in this study provides a broad, structured overview of research in the field of smart services. A systematic search led to 109 publications dealing with smart services in the ISR field. The research context of the resulting literature is diverse and reflects the applicability of smart services in several industries (e.g., manufacturing, health, city).

To provide a better overview, the articles were categorized based on the phases of the smart service lifecycle that they covered. Next, the publications were classified according to their thematic focus. During the literature analysis phase, 13 topics were defined based on the focus of the articles (e.g., technologies, (big) data, standardization). Each publication covered at least one of these topics. A summary in the form of a heat map demonstrated the research intensity of topics regarding smart services. Possible research gaps were identified from the heat map (e.g., measuring and predicting customer's behavior, role of knowledge management, using established machine learning methods for smart services).

The fact that several publications may have covered the same topic and lifecycle phase does not necessarily mean that no more research is required. Research is still needed in certain fields of technology and data in the context of smart services, even though these topics have been frequently discussed. A general approach considering e.g. the roles and different functions of technology and big data is still missing. In past publications topics related to technologies and big data are rather discussed for a specific field or application. Part from looking at specific forms of smart services enables to take an overall view in order to deepen the global understanding. Nevertheless, it must be ensured that the approaches are not too shallow without providing added value.

The heat map shows that only a few topics have been a major focus of research. Although the importance of the customer's role is undisputed in the literature, this aspect has rarely been examined. On the one hand it is postulated that focusing on the customer is the key for successful smart services. On the other hand, this importance is not reflected in the number of publications dealing with the customer in the context of such services. Especially looking at the customer during the operation phase might provide interesting insights that are helpful for smart service research. Taking a broader view, overall findings of how to involve the customer and considering the usage behavior across all phases of the lifecycle are not yet investigated. This is important because it does not have to be neglected that the better the customer and the customer's behavior is understood, the better and more precise appropriate smart services can be provided.

Economic aspects, such as the development of business models or pricing strategies, have rarely been discussed in the literature. For providers it is valid that offering smart services is only reasonable if it is profitable. But how to identify profitability and examining which information is necessary to make a feasibility study is yet to be explored. Investigating in what sense known business models are changing through smart services helps to understand how they work in practice.

The research of knowledge management and machine learning in the field of smart services stands mostly at the very beginning. This is interesting because especially for this type of service data interpretation is important. Smart services are frequently adapted to meet the customer's requirements. Knowledge gained from past events, employees and further sources enables to continually improve them. Machine learning enables to turn data into information what also contributes to continual improvement. As smart services are a relatively new development, best practice approaches are not yet established. Research that investigates suggestions of how knowledge management and machine learning for smart services can be designed is interesting both for theory and practice. Related to the design it is also necessary to investigate how to embed it into the different contexts.

Not only the thematic focus is limited to only a few topics, but there is also a clear focus along the lifecycle. While both the design phase and the implementation phase have been frequently discussed, the operation of smart services has been neglected. This phase seems to be more practice-oriented than the other phases which provides great potential for research. Case studies are an appropriate opportunity to gain an insight into what the most important topics in practice are. The results help to improve theoretically developed results, such as models or frameworks. Therefore, detailed investigations are useful to both theory and practice.

To sum up, this article presented and discussed concrete ideas for further research that will help to draw a clearer and more comprehensive picture of smart services in the academic literature as well as for practical applications. 


\section{Appendix 1}

Table 4 Number of hits in the databases

\begin{tabular}{|c|c|c|c|c|}
\hline Database & Keyword & $\begin{array}{l}\text { Results through } \\
\text { keyword search }\end{array}$ & $\begin{array}{l}\text { Articles after applying } \\
\text { formal criteria }\end{array}$ & $\begin{array}{l}\text { Articles after } \\
\text { screening manually }\end{array}$ \\
\hline \multirow[t]{3}{*}{$\mathrm{ACM}$} & • "smart service" OR "smart services" & 26 & 19 & 8 \\
\hline & • "digital service" OR "digital services" & 53 & 48 & 2 \\
\hline & $\begin{array}{l}\text { - "electronic service" OR "electronic services" OR } \\
\text { "e-service" OR "e-services }\end{array}$ & 234 & 214 & 3 \\
\hline \multirow[t]{3}{*}{ AISeL } & • "smart service" OR "smart services" & 3 & 1 & 1 \\
\hline & • "digital service" OR "digital services" & 48 & 47 & 3 \\
\hline & $\begin{array}{l}\text { • "electronic service" OR "electronic services" OR } \\
\text { "e-service" OR "e-services" }\end{array}$ & 167 & 161 & 2 \\
\hline \multirow[t]{3}{*}{ Emerald Insight } & • "smart service" OR "smart services" & 12 & 10 & 1 \\
\hline & • "digital service" OR "digital services" & 1110 & 331 & 0 \\
\hline & $\begin{array}{l}\text { - "electronic service" OR "electronic services" OR } \\
\text { "e-service" OR "e-services" }\end{array}$ & 366 & 180 & 0 \\
\hline \multirow[t]{3}{*}{ IEEExplore } & • "smart service” OR “smart services" & 180 & 153 & 45 \\
\hline & • "digital service" OR "digital services" & 325 & 316 & 5 \\
\hline & $\begin{array}{l}\text { • "electronic service" OR "electronic services" OR } \\
\text { "e-service" OR "e-services" }\end{array}$ & 3374 & 3182 & 7 \\
\hline \multirow[t]{3}{*}{ InformsOnline } & • "smart service" OR "smart services" & 9 & 2 & 1 \\
\hline & • "digital service" OR "digital services" & 18 & 13 & 0 \\
\hline & $\begin{array}{l}\text { • "electronic service" OR "electronic services" OR } \\
\text { "e-service" OR "e-services" }\end{array}$ & 62 & 42 & 0 \\
\hline \multirow[t]{3}{*}{ JSTOR } & • "smart service" OR “smart services" & 27 & 9 & 0 \\
\hline & • "digital service" OR "digital services" & 523 & 252 & 0 \\
\hline & $\begin{array}{l}\text { - "electronic service" OR "electronic services" OR } \\
\text { "e-service" OR "e-services }\end{array}$ & 3261 & 1309 & 0 \\
\hline \multirow[t]{3}{*}{ Science Direct } & • "smart service" OR "smart services" & 22 & 19 & 5 \\
\hline & • "digital service" OR "digital services" & 61 & 50 & 1 \\
\hline & $\begin{array}{l}\text { • "electronic service" OR "electronic services" OR } \\
\text { "e-service" OR "e-services" }\end{array}$ & 379 & 357 & 0 \\
\hline \multirow[t]{3}{*}{ SpringerLink } & • "smart service" OR "smart services" & 1010 & 167 & 13 \\
\hline & • "digital service" OR "digital services" & 2077 & 400 & 1 \\
\hline & $\begin{array}{l}\text { • "electronic service" OR "electronic services" OR } \\
\text { "e-service" OR "e-services" }\end{array}$ & 11,709 & 2730 & 1 \\
\hline Total number of articles & & 25,056 & 10,012 & 99 \\
\hline
\end{tabular}

\section{Appendix 2}

Table 5 Outlets that are selected more than one time
Outlet

Frequency

Proceedings of the Hawaii International Conference on System Sciences

Proceedings of the International Conference on Information Systems

3

Proceedings of the Annual SRII Global Conference

Proceedings of the Wuhan International Conference on e-Business

3

Proceedings of the International Conference on Electronic Commerce

Proceedings of the International Conference on Industrial Informatics and International Conference on Autonomic and Trusted Computing

Service Business

Proceedings of the Annual ACM Symposium on Applied Computing 2

Proceedings of the IEEE Symposium on Computers and Communication 2

IEEE Transactions on Consumer Electronics
2

2

3
2
2
2
2




\section{Appendix 3}

Table 6 Publications categorized by research context and target group

\begin{tabular}{|c|c|c|}
\hline Author & Research context & $\begin{array}{l}\text { Target } \\
\text { group }\end{array}$ \\
\hline Abbate et al. (2015) & General & $\mathrm{B} 2 \mathrm{~B}$ \\
\hline Abdellatif et al. (2013) & Government & $\mathrm{B} 2 \mathrm{C}$ \\
\hline Adeleke and AbdulRahman (2011) & Government & $\mathrm{B} 2 \mathrm{C}$ \\
\hline Al Nuaimi et al. (2015) & City & $\mathrm{B} 2 \mathrm{C}$ \\
\hline Allmendinger and Lombreglia (2005) & Manufacturing & $\mathrm{B} 2 \mathrm{~B}$ \\
\hline Alti et al. (2015) & Health & $\mathrm{B} 2 \mathrm{C}$ \\
\hline Anthopoulos and Fitsilis (2014) & City & $\mathrm{B} 2 \mathrm{C}$ \\
\hline Anthopoulos et al. (2016) & City & $\mathrm{B} 2 \mathrm{C}$ \\
\hline Anttiroiko et al. (2014) & City & $\mathrm{B} 2 \mathrm{~B}$ \\
\hline Baldoni et al. (2010) & Home & $\mathrm{B} 2 \mathrm{C}$ \\
\hline Barile and Polese (2010) & General & Both \\
\hline Batubara (2015) & General, health & $\mathrm{B} 2 \mathrm{C}$ \\
\hline Bedogni et al. (2013) & Mobility & $\mathrm{B} 2 \mathrm{C}$ \\
\hline Berna-Martinez et al. (2006) & $\begin{array}{l}\text { Manufacturing, } \\
\text { robotic }\end{array}$ & Both \\
\hline Böcker et al. (2010) & General, health & $\mathrm{B} 2 \mathrm{C}$ \\
\hline Brotman et al. (2015) & Home & $\mathrm{B} 2 \mathrm{C}$ \\
\hline Buchanan and McMenemy (2012) & Health, library & $\mathrm{B} 2 \mathrm{C}$ \\
\hline Buettner (2016) & General & $\mathrm{B} 2 \mathrm{C}$ \\
\hline Byun and Park (2011) & Building & Both \\
\hline Calza et al. (2015) & Manufacturing & Both \\
\hline Cardozo and Clarke (2015) & City & $\mathrm{B} 2 \mathrm{C}$ \\
\hline Cellary (2013) & Manufacturing & $\mathrm{B} 2 \mathrm{C}$ \\
\hline Chatterjee and Armentano (2015) & Health & $\mathrm{B} 2 \mathrm{C}$ \\
\hline Chen et al. (2012) & General & $\mathrm{B} 2 \mathrm{C}$ \\
\hline Chu and Lin (2011) & General & Both \\
\hline Ciortea et al. (2016) & General & $\mathrm{B} 2 \mathrm{C}$ \\
\hline Dawid et al. (2016) & General & $\mathrm{B} 2 \mathrm{C}$ \\
\hline De Oliveira and Silva (2015) & Grid & $\mathrm{B} 2 \mathrm{C}$ \\
\hline Delfanti et al. (2015) & City, grid & $\mathrm{B} 2 \mathrm{~B}$ \\
\hline Domingues et al. (2010) & General & Both \\
\hline Fan et al. (2012) & Grid & Both \\
\hline Fan et al. (2016) & Manufacturing & $\mathrm{B} 2 \mathrm{C}$ \\
\hline Ferretti et al. (2016) & City & $\mathrm{B} 2 \mathrm{C}$ \\
\hline Ferretti and D'Angelo (2016) & City & $\mathrm{B} 2 \mathrm{C}$ \\
\hline Georgakopoulos and Jayaraman (2016) & General & $\mathrm{B} 2 \mathrm{C}$ \\
\hline Geum et al. (2016) & General & Both \\
\hline Gillig and Sailer (2012) & General & $\mathrm{B} 2 \mathrm{C}$ \\
\hline Gretzel et al. (2015) & Tourism & Both \\
\hline Hamdan et al. (2012) & General & $\mathrm{B} 2 \mathrm{~B}$ \\
\hline He et al. (2012) & Website/app & $\mathrm{B} 2 \mathrm{C}$ \\
\hline Holgado and Macchi (2014) & Manufacturing & $\mathrm{B} 2 \mathrm{~B}$ \\
\hline Hong et al. (2014) & Website/app & $\mathrm{B} 2 \mathrm{C}$ \\
\hline Jerald et al. (2016) & General & Both \\
\hline Kamp et al. (2016) & Manufacturing & $\mathrm{B} 2 \mathrm{~B}$ \\
\hline Kennedy and Keskin (2016) & Manufacturing & $\mathrm{B} 2 \mathrm{C}$ \\
\hline Keskin and Kennedy (2015) & Manufacturing & Both \\
\hline Kim et al. (2015) & Health, Home & $\mathrm{B} 2 \mathrm{C}$ \\
\hline Knote and Blohm (2016) & General & $\mathrm{B} 2 \mathrm{C}$ \\
\hline Kölmel and Bulander (2015) & Manufacturing & Both \\
\hline Korzun et al. (2015) & Health & $\mathrm{B} 2 \mathrm{C}$ \\
\hline Kryvinska et al. (2008) & Telecommunications & $\mathrm{B} 2 \mathrm{C}$ \\
\hline Kuebel and Zarnekow (2015) & Home & Both \\
\hline Kwak et al. (2014) & General & $\mathrm{B} 2 \mathrm{C}$ \\
\hline Kynsilehto and Olsson (2011) & General & $\mathrm{B} 2 \mathrm{C}$ \\
\hline Kynsilehto and Olsson (2012) & General, home & $\mathrm{B} 2 \mathrm{C}$ \\
\hline Lê Tuán et al. (2012) & City & $\mathrm{B} 2 \mathrm{C}$ \\
\hline
\end{tabular}

Table 6 (continued)

\begin{tabular}{|c|c|c|}
\hline Author & Research context & $\begin{array}{l}\text { Target } \\
\text { group }\end{array}$ \\
\hline Lebedev et al. (2016) & Health & $\mathrm{B} 2 \mathrm{C}$ \\
\hline Lee et al. (2010) & General & $\mathrm{B} 2 \mathrm{C}$ \\
\hline Lee et al. (2012) & General & $\mathrm{B} 2 \mathrm{C}$ \\
\hline Lee et al. (2015) & Home & $\mathrm{B} 2 \mathrm{C}$ \\
\hline Lee et al. (2016) & General & $\mathrm{B} 2 \mathrm{C}$ \\
\hline Lesjak et al. (2014) & Manufacturing & $\mathrm{B} 2 \mathrm{~B}$ \\
\hline Lesjak et al. (2015) & Manufacturing & $\mathrm{B} 2 \mathrm{~B}$ \\
\hline Li et al. (2015) & Health & $\mathrm{B} 2 \mathrm{~B}$ \\
\hline Ma et al. (2010) & Health, home, robotic & $\mathrm{B} 2 \mathrm{C}$ \\
\hline Maleshkova et al. (2016) & Website/app & $\mathrm{B} 2 \mathrm{C}$ \\
\hline Martin et al. (2004) & Government & $\mathrm{B} 2 \mathrm{C}$ \\
\hline Massink et al. (2010) & General & $\mathrm{B} 2 \mathrm{C}$ \\
\hline Mathes et al. (2009) & Manufacturing & $\mathrm{B} 2 \mathrm{~B}$ \\
\hline Mihaylov et al. (2015) & Health & $\mathrm{B} 2 \mathrm{C}$ \\
\hline Mihovska et al. (2015) & General, health & Both \\
\hline Mo et al. (2010) & General & $\mathrm{B} 2 \mathrm{C}$ \\
\hline Moawad et al. (2015) & Home & $\mathrm{B} 2 \mathrm{C}$ \\
\hline Mukudu et al. (2016) & City & Both \\
\hline Nakajima et al. (2012) & Health & $\mathrm{B} 2 \mathrm{C}$ \\
\hline Oh et al. (2010) & City & $\mathrm{B} 2 \mathrm{~B}$ \\
\hline Oslislo et al. (2011) & Home & $\mathrm{B} 2 \mathrm{~B}$ \\
\hline Paluch and Wünderlich (2016) & General & $\mathrm{B} 2 \mathrm{~B}$ \\
\hline Pao et al. (2011) & Manufacturing & $\mathrm{B} 2 \mathrm{C}$ \\
\hline Perera et al. (2014) & City & Both \\
\hline Pistofidis and Emmanouilidis (2012) & Manufacturing & Both \\
\hline Priller et al. (2014) & Manufacturing & $\mathrm{B} 2 \mathrm{~B}$ \\
\hline Ren et al. (2014) & General & Both \\
\hline Roduner and Langheinrich (2010) & General & $\mathrm{B} 2 \mathrm{C}$ \\
\hline Sakakibara et al. (2016) & City & $\mathrm{B} 2 \mathrm{C}$ \\
\hline Seeliger et al. (2015) & Tourism & $\mathrm{B} 2 \mathrm{C}$ \\
\hline Singhai and Faizan (2016) & Government & $\mathrm{B} 2 \mathrm{C}$ \\
\hline Smirnov et al. (2015) & Home & $\mathrm{B} 2 \mathrm{C}$ \\
\hline Smith et al. (2016) & Website/app & $\mathrm{B} 2 \mathrm{C}$ \\
\hline Son et al. (2011) & Home & $\mathrm{B} 2 \mathrm{C}$ \\
\hline Spottke et al. (2016) & General & $\mathrm{B} 2 \mathrm{C}$ \\
\hline Strüker and Kerschbaum (2012) & Grid & Both \\
\hline Tantatsanawong et al. (2011) & Education & $\mathrm{B} 2 \mathrm{C}$ \\
\hline Theocharis and Tsihrintzis (2013) & Government & $\mathrm{B} 2 \mathrm{~B}$ \\
\hline Tianyong et al. (2006) & General & $\mathrm{B} 2 \mathrm{~B}$ \\
\hline Tien (2012) & $\begin{array}{l}\text { General, } \\
\text { manufacturing }\end{array}$ & Both \\
\hline Wang et al. (2011) & Manufacturing & $\mathrm{B} 2 \mathrm{C}$ \\
\hline Wang et al. (2012) & General & Both \\
\hline Weijie et al. (2012) & Health & $\mathrm{B} 2 \mathrm{C}$ \\
\hline Westwood and Cazier (2016) & Health & $\mathrm{B} 2 \mathrm{C}$ \\
\hline Williams et al. (2008) & Website/app & $\mathrm{B} 2 \mathrm{C}$ \\
\hline Wünderlich et al. (2012) & General & Both \\
\hline Wünderlich et al. (2015) & General & Both \\
\hline Yachir et al. (2009) & Health, robotic & $\mathrm{B} 2 \mathrm{C}$ \\
\hline Yang et al. (2015) & Health & $\mathrm{B} 2 \mathrm{C}$ \\
\hline Yong and Hiu-ying (2013) & Tourism & $\mathrm{B} 2 \mathrm{C}$ \\
\hline Yu (2004) & Manufacturing & $\mathrm{B} 2 \mathrm{C}$ \\
\hline Zhang and Qi (2011) & Grid & $\mathrm{B} 2 \mathrm{C}$ \\
\hline Zo (2003) & Website/app & $\mathrm{B} 2 \mathrm{C}$ \\
\hline
\end{tabular}




\section{Appendix 4}

Fig. 5 a Origins of first authors. b Target groups of smart services a

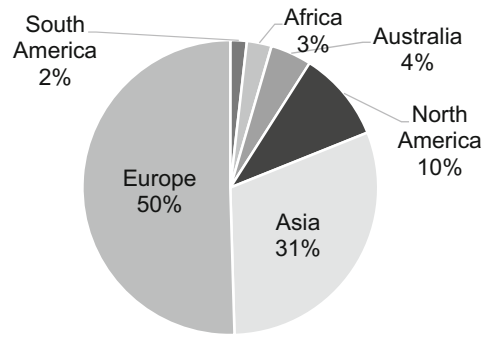

b

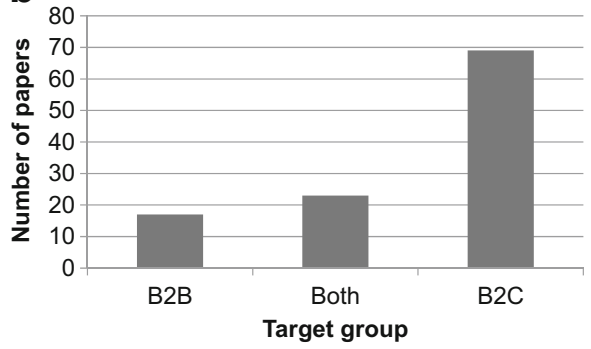

\section{Appendix 5}

Table 7 Publications assigned to the fields of the heat map

\begin{tabular}{|c|c|c|c|c|c|}
\hline Topic & Service strategy & Service design & Service transition & Service operation & Service improvement \\
\hline \multirow[t]{25}{*}{ Technologies } & $\begin{array}{l}\text { Allmendinger and } \\
\text { Lombreglia (2005) }\end{array}$ & Alti et al. (2015) & Byun and Park (2011) & Baldoni et al. (2010) & Böcker et al. (2010) \\
\hline & $\begin{array}{l}\text { Ferretti and D'Angelo } \\
\quad(2016)\end{array}$ & Anttiroiko et al. (2014) & Ferretti et al. (2016) & $\begin{array}{l}\text { Chatterjee and } \\
\text { Armentano (2015) }\end{array}$ & Fan et al. (2012) \\
\hline & $\begin{array}{l}\text { Georgakopoulos and } \\
\text { Jayaraman (2016) }\end{array}$ & Berna-Martinez et al. (2006) & $\begin{array}{r}\text { Georgakopoulos and } \\
\text { Jayaraman (2016) }\end{array}$ & Hamdan et al. (2012) & Kim et al. (2015) \\
\hline & $\begin{array}{l}\text { Holgado and Macchi } \\
\text { (2014) }\end{array}$ & Brotman et al. (2015) & Kryvinska et al. (2008) & & $\begin{array}{l}\text { Kryvinska et al. } \\
\text { (2008) }\end{array}$ \\
\hline & Kamp et al. (2016) & Cardozo and Clarke (2015) & Lê Tuán et al. (2012) & & $\begin{array}{l}\text { Kynsilehto and Olsson } \\
\text { (2011) }\end{array}$ \\
\hline & Lê Tuán et al. (2012) & Ciortea et al. (2016) & Lebedev et al. (2016) & & Oslislo et al. (2011) \\
\hline & Lee et al. (2012) & Delfanti et al. (2015) & Lee et al. (2015) & & $\begin{array}{l}\text { Singhai and Faizan } \\
\text { (2016) }\end{array}$ \\
\hline & $\begin{array}{l}\text { Paluch and Wünderlich } \\
\text { (2016) }\end{array}$ & Domingues et al. (2010) & Lesjak et al. (2014) & & Smirnov et al. (2015) \\
\hline & Perera et al. (2014) & Ferretti and D'Angelo (2016) & Lesjak et al. (2015) & & \\
\hline & Spottke et al. (2016) & Geum et al. (2016) & Ma et al. (2010) & & \\
\hline & Tianyong et al. (2006) & Gretzel et al. (2015) & $\begin{array}{l}\text { Maleshkova et al. } \\
\text { (2016) }\end{array}$ & & \\
\hline & & Jerald et al. (2016) & Mathes et al. (2009) & & \\
\hline & & Kamp et al. (2016) & Mihovska et al. (2015) & & \\
\hline & & Kim et al. (2015) & Mukudu et al. (2016) & & \\
\hline & & Kryvinska et al. (2008) & Oh et al. (2010) & & \\
\hline & & Kuebel and Zarnekow (2015) & $\begin{array}{l}\text { Paluch and Wünderlich } \\
\text { (2016) }\end{array}$ & & \\
\hline & & Lebedev et al. (2016) & $\begin{array}{l}\text { Pistofidis and } \\
\text { Emmanouilidis } \\
\text { (2012) }\end{array}$ & & \\
\hline & & Lee et al. (2015) & Ren et al. (2014) & & \\
\hline & & Maleshkova et al. (2016) & $\begin{array}{l}\text { Roduner and } \\
\quad \text { Langheinrich (2010) }\end{array}$ & & \\
\hline & & Mathes et al. (2009) & Sakakibara et al. (2016) & & \\
\hline & & Mihovska et al. (2015) & Seeliger et al. (2015) & & \\
\hline & & Nakajima et al. (2012) & $\begin{array}{l}\text { Strüker and } \\
\quad \text { Kerschbaum (2012) }\end{array}$ & & \\
\hline & & Priller et al. (2014) & $\begin{array}{l}\text { Westwood and Cazier } \\
\text { (2016) }\end{array}$ & & \\
\hline & & $\begin{array}{l}\text { Roduner and Langheinrich } \\
\text { (2010) }\end{array}$ & Zhang and Qi (2011) & & \\
\hline & & Wünderlich et al. (2012) & & & \\
\hline
\end{tabular}


Table 7 (continued)

\begin{tabular}{|c|c|c|c|c|c|}
\hline Topic & Service strategy & Service design & Service transition & Service operation & Service improvement \\
\hline \multirow[t]{21}{*}{ (Big) data } & $\begin{array}{l}\text { Allmendinger and } \\
\text { Lombreglia (2005) }\end{array}$ & Abdellatif et al. (2013) & Al Nuaimi et al. (2015) & $\begin{array}{l}\text { Chatterjee and } \\
\text { Armentano (2015) }\end{array}$ & Fan et al. (2012) \\
\hline & $\begin{array}{l}\text { Georgakopoulos and } \\
\text { Jayaraman (2016) }\end{array}$ & Alti et al. (2015) & Bedogni et al. (2013) & Lee et al. (2010) & Mihaylov et al. (2015) \\
\hline & $\begin{array}{l}\text { Holgado and Macchi } \\
\text { (2014) }\end{array}$ & Batubara (2015) & Chu and Lin (2011) & \multirow[t]{19}{*}{ Yachir et al. (2009) } & $\begin{array}{l}\text { Singhai and Faizan } \\
\text { (2016) }\end{array}$ \\
\hline & $\begin{array}{l}\text { Keskin and Kennedy } \\
\text { (2015) }\end{array}$ & Buettner (2016) & Ferretti et al. (2016) & & Wang et al. (2011) \\
\hline & Lee et al. (2012) & Cellary (2013) & $\begin{array}{r}\text { Georgakopoulos and } \\
\text { Jayaraman (2016) }\end{array}$ & & Yu (2004) \\
\hline & Perera et al. (2014) & Domingues et al. (2010) & Kamp et al. (2016) & & \\
\hline & Smith et al. (2016) & Geum et al. (2016) & Lê Tuán et al. (2012) & & \\
\hline & \multirow[t]{14}{*}{ Tien (2012) } & Gretzel et al. (2015) & Lesjak et al. (2014) & & \\
\hline & & Keskin and Kennedy (2015) & Lesjak et al. (2015) & & \\
\hline & & Korzun et al. (2015) & Li et al. (2015) & & \\
\hline & & Maleshkova et al. (2016) & $\begin{array}{l}\text { Maleshkova et al. } \\
\text { (2016) }\end{array}$ & & \\
\hline & & Mihaylov et al. (2015) & Mihovska et al. (2015) & & \\
\hline & & Mihovska et al. (2015) & Mo et al. (2010) & & \\
\hline & & Mo et al. (2010) & Mukudu et al. (2016) & & \\
\hline & & Moawad et al. (2015) & Ren et al. (2014) & & \\
\hline & & Priller et al. (2014) & Sakakibara et al. (2016) & & \\
\hline & & Smith et al. (2016) & Son et al. (2011) & & \\
\hline & & Son et al. (2011) & $\begin{array}{l}\text { Strüker and } \\
\text { Kerschbaum (2012) }\end{array}$ & & \\
\hline & & Tien (2012) & Westwood and Cazier & & \\
\hline & & Weijie et al. (2012) & (2016) & & \\
\hline & & Wünderlich et al. (2015) & & & \\
\hline \multirow[t]{15}{*}{ Standardization } & Dawid et al. (2016) & Anthopoulos et al. (2016) & Al Nuaimi et al. (2015) & & Böcker et al. (2010) \\
\hline & Lê Tuán et al. (2012) & Berna-Martinez et al. (2006) & Bedogni et al. (2013) & & Singhai and Faizan \\
\hline & Martin et al. (2004) & Ciortea et al. (2016) & Lê Tuán et al. (2012) & & (2016) \\
\hline & \multirow[t]{12}{*}{ Tien (2012) } & De Oliveira and Silva (2015) & Lesjak et al. (2014) & & \\
\hline & & Fan et al. (2016) & Lesjak et al. (2015) & & \\
\hline & & Kölmel and Bulander (2015) & Ma et al. (2010) & & \\
\hline & & Kryvinska et al. (2008) & $\begin{array}{l}\text { Maleshkova et al. } \\
\text { (2016) }\end{array}$ & & \\
\hline & & Maleshkova et al. (2016) & Martin et al. (2004) & & \\
\hline & & Martin et al. (2004) & Mathes et al. (2009) & & \\
\hline & & Mathes et al. (2009) & Mihovska et al. (2015) & & \\
\hline & & Mihaylov et al. (2015) & Mukudu et al. (2016) & & \\
\hline & & Mihovska et al. (2015) & Oh et al. (2010) & & \\
\hline & & Priller et al. (2014) & Sakakibara et al. (2016) & & \\
\hline & & Smith et al. (2016) & & & \\
\hline & & Tien (2012) & & & \\
\hline \multirow[t]{12}{*}{ Security/privacy } & Dawid et al. (2016) & Buettner (2016) & Al Nuaimi et al. (2015) & \multirow{12}{*}{$\begin{array}{l}\text { Chatterjee and } \\
\text { Armentano (2015) }\end{array}$} & Fan et al. (2012) \\
\hline & Lê Tuán et al. (2012) & Cellary (2013) & Kryvinska et al. (2008) & & $\begin{array}{l}\text { Kuebel and Zarnekow } \\
\text { (2015) }\end{array}$ \\
\hline & Martin et al. (2004) & Delfanti et al. (2015) & Lê Tuán et al. (2012) & & $\begin{array}{l}\text { Kynsilehto and Olsson } \\
\text { (2012) }\end{array}$ \\
\hline & \multirow[t]{9}{*}{ Tien (2012) } & Domingues et al. (2010) & Lesjak et al. (2014) & & \multirow{9}{*}{$\begin{array}{l}\text { Singhai and Faizan } \\
\quad(2016)\end{array}$} \\
\hline & & & Lesjak et al. (2015) & & \\
\hline & & Fan et al. (2016) & Martin et al. (2004) & & \\
\hline & & Gretzel et al. (2015) & $\begin{array}{l}\text { Paluch and Wünderlich } \\
\text { (2016) }\end{array}$ & & \\
\hline & & Jerald et al. (2016) & $\begin{array}{l}\text { Roduner and } \\
\text { Langheinrich (2010) }\end{array}$ & & \\
\hline & & Keskin and Kennedy (2015) & Sakakibara et al. (2016) & & \\
\hline & & Kuebel and Zarnekow (2015) & Strüker and & & \\
\hline & & Martin et al. (2004) & Kerschbaum (2012) & & \\
\hline & & Moawad et al. (2015) & & & \\
\hline
\end{tabular}


Table 7 (continued)

\begin{tabular}{|c|c|c|c|c|c|}
\hline Topic & Service strategy & Service design & Service transition & Service operation & Service improvement \\
\hline & & Priller et al. (2014) & & & \\
\hline & & $\begin{array}{l}\text { Roduner and Langheinrich } \\
\text { (2010) }\end{array}$ & & & \\
\hline & & Tien $(2012)$ & & & \\
\hline \multirow[t]{11}{*}{ Service quality } & Barile and Polese (2010) & Abbate et al. (2015) & $\begin{array}{l}\text { Adeleke and } \\
\text { AbdulRahman } \\
\text { (2011) }\end{array}$ & Yachir et al. (2009) & Chen et al. (2012) \\
\hline & Calza et al. (2015) & Barile and Polese (2010) & Kwak et al. (2014) & & Fan et al. (2012) \\
\hline & Lee et al. (2012) & Buettner (2016) & Lesjak et al. (2015) & & Hong et al. (2014) \\
\hline & Wang et al. (2012) & Chen et al. (2012) & Mo et al. (2010) & & Kwak et al. (2014) \\
\hline & Zo (2003) & Delfanti et al. (2015) & Zo (2003) & & $\begin{array}{l}\text { Tantatsanawong et al. } \\
\text { (2011) }\end{array}$ \\
\hline & & He et al. (2012) & & & Yachir et al. (2009) \\
\hline & & Smith et al. (2016) & & & Yu (2004) \\
\hline & & Tantatsanawong et al. (2011) & & & \\
\hline & & Wang et al. (2012) & & & \\
\hline & & Yachir et al. (2009) & & & \\
\hline & & Yong and Hui-ying (2013) & & & \\
\hline \multirow{12}{*}{$\begin{array}{l}\text { Customer } \\
\text { involvement }\end{array}$} & Allmendinger and & Brotman et al. (2015) & Adeleke and & Yachir et al. (2009) & Buchanan and \\
\hline & Lombreglia (2005) & Buchanan and McMenemy & AbdulRahman & & McMenemy (2012) \\
\hline & Gillig and Sailer (2012) & $(2012)$ & $(2011)$ & & Kuebel and Zarnekow \\
\hline & Spottke et al. (2016) & Gillig and Sailer (2012) & Mihovska et al. (2015) & & (2015) \\
\hline & Wang et al. (2012) & He et al. (2012) & Mukudu et al. (2016) & & Wang et al. (2011) \\
\hline & Zo (2003) & Kuebel and Zarnekow (2015) & Paluch and Wünderlich & & Yachir et al. (2009) \\
\hline & & Mihovska et al. (2015) & (2016) & & \\
\hline & & Son et al. (2011) & Son et al. (2011) & & \\
\hline & & Wang et al. (2012) & Zhang and Qi (2011) & & \\
\hline & & Wünderlich et al. (2012) & Zo (2003) & & \\
\hline & & Yachir et al. (2009) & & & \\
\hline & & Yong and Hui-ying (2013) & & & \\
\hline \multirow[t]{11}{*}{ Trends } & Abbate et al. (2015) & Abbate et al. (2015) & $\begin{array}{l}\text { Maleshkova et al. } \\
\text { (2016) }\end{array}$ & & \\
\hline & Dawid et al. (2016) & Anttiroiko et al. (2014) & Mihovska et al. (2015) & & \\
\hline & Perera et al. (2014) & Brotman et al. (2015) & & & \\
\hline & Tianyong et al. (2006) & Gretzel et al. (2015) & & & \\
\hline & $\begin{array}{l}\text { Wünderlich et al. } \\
\text { (2015) }\end{array}$ & $\begin{array}{l}\text { Kölmel and Bulander (2015) } \\
\text { Lee et al. (2016) }\end{array}$ & & & \\
\hline & & Maleshkova et al. (2016) & & & \\
\hline & & Mihovska et al. (2015) & & & \\
\hline & & Tantatsanawong et al. (2011) & & & \\
\hline & & Wünderlich et al. (2012) & & & \\
\hline & & Wünderlich et al. (2015) & & & \\
\hline & & Yong and Hui-ying (2013) & & & \\
\hline \multirow[t]{7}{*}{ User interface } & & Fan et al. (2016) & Bedogni et al. (2013) & Hamdan et al. (2012) & Böcker et al. (2010) \\
\hline & & He et al. (2012) & Li et al. (2015) & & $\begin{array}{l}\text { Kynsilehto and Olsson } \\
\text { (2011) }\end{array}$ \\
\hline & & Kim et al. (2015) & Mukudu et al. (2016) & & Yu (2004) \\
\hline & & Massink et al. (2010) & Oh et al. (2010) & & \\
\hline & & Nakajima et al. (2012) & Pao et al. (2011) & & \\
\hline & & $\begin{array}{l}\text { Roduner and Langheinrich } \\
\text { (2010) }\end{array}$ & Seeliger et al. (2015) & & \\
\hline & & Tien (2012) & & & \\
\hline \multirow[t]{4}{*}{ Usage behavior } & Perera et al. (2014) & Kuebel and Zarnekow (2015) & Seeliger et al. (2015) & & Böcker et al. (2010) \\
\hline & Spottke et al. (2016) & Massink et al. (2010) & Yang et al. (2015) & & $\begin{array}{l}\text { Kuebel and Zarnekow } \\
\text { (2015) }\end{array}$ \\
\hline & Zo (2003) & Wünderlich et al. (2012) & & & $\begin{array}{l}\text { Kynsilehto and Olsson } \\
\text { (2011) }\end{array}$ \\
\hline & & Yang et al. (2015) & & & $\begin{array}{l}\text { Kynsilehto and Olsson } \\
\text { (2012) }\end{array}$ \\
\hline \multirow[t]{2}{*}{ Business models } & $\begin{array}{l}\text { Allmendinger and } \\
\text { Lombreglia (2005) }\end{array}$ & Gretzel et al. (2015) & $\begin{array}{l}\text { Anthopoulos and Fitsilis } \\
\text { (2014) }\end{array}$ & & \\
\hline & Gillig and Sailer (2012) & Kamp et al. (2016) & Kamp et al. (2016) & & \\
\hline
\end{tabular}


Table 7 (continued)

\begin{tabular}{|c|c|c|c|c|c|}
\hline Topic & Service strategy & Service design & Service transition & Service operation & Service improvement \\
\hline & $\begin{array}{l}\text { Kamp et al. (2016) } \\
\text { Keskin and Kennedy } \\
\quad(2015) \\
\text { Wünderlich et al. } \\
\quad(2015)\end{array}$ & $\begin{array}{l}\text { Keskin and Kennedy (2015) } \\
\text { Wünderlich et al. (2015) }\end{array}$ & $\begin{array}{l}\text { Knote and Blohm } \\
\text { (2016) }\end{array}$ & & \\
\hline $\begin{array}{l}\text { Knowledge } \\
\text { management }\end{array}$ & Tianyong et al. (2006) & $\begin{array}{l}\text { Moawad et al. (2015) } \\
\text { Theocharis and Tsihrintzis } \\
\text { (2013) }\end{array}$ & $\begin{array}{l}\text { Chu and Lin (2011) } \\
\text { Li et al. (2015) }\end{array}$ & $\begin{array}{l}\text { Chatterjee and } \\
\text { Armentano (2015) }\end{array}$ & $\begin{array}{l}\text { Theocharis and } \\
\text { Tsihrintzis (2013) } \\
\text { Wang et al. (2011) }\end{array}$ \\
\hline Pricing & $\begin{array}{l}\text { Kennedy and Keskin } \\
\quad(2016) \\
\text { Keskin and Kennedy } \\
\quad(2015) \\
\text { Tien (2012) } \\
\text { Williams et al. (2008) }\end{array}$ & Williams et al. (2008) & $\begin{array}{l}\text { Al Nuaimi et al. (2015) } \\
\text { Kennedy and Keskin } \\
\quad(2016)\end{array}$ & & \\
\hline Machine learning & & $\begin{array}{l}\text { Abdellatif et al. (2013) } \\
\text { Buettner (2016) }\end{array}$ & Kamp et al. (2016) & & $\begin{array}{l}\text { Fan et al. (2012) } \\
\text { Wang et al. (2011) }\end{array}$ \\
\hline
\end{tabular}

Open Access This article is distributed under the terms of the Creative Commons Attribution 4.0 International License (http:// creativecommons.org/licenses/by/4.0/), which permits unrestricted use, distribution, and reproduction in any medium, provided you give appropriate credit to the original author(s) and the source, provide a link to the Creative Commons license, and indicate if changes were made.

Publisher's note Springer Nature remains neutral with regard to jurisdictional claims in published maps and institutional affiliations.

\section{References}

Abbate, T., de Luca, D., Gaeta, A., Lepore, M., Miranda, S., \& Perano, M. (2015). Analysis of open innovation intermediaries platforms by considering the smart service system perspective. Procedia Manufacturing, 3, 3575-3582.

Abdellatif, A., Amor, N. B., \& Mellouli, S. (2013). An intelligent framework for e-government personalized services. In Proceedings of the 14th Annual International Conference on Digital Government Research, Quebec City, Canada, June 17-20, 2013 (pp. 120-126).

Adeleke, I. A., \& AbdulRahman, A. (2011). Co-creation of value: Applying the paradigm to government e-service. In Proceedings of the 2nd International Conference on Research and Innovation in Information Systems, Kuala Lumpur, Malaysia, November 23-24, 2011 (pp. 201-206).

Al Nuaimi, E., Al Neyadi, H., Mohamed, N., \& Al-Jaroodi, J. (2015). Applications of big data to smart cities. Journal of Internet Services and Applications, 6(25), 1-15.

Alahmadi, M., \& Qureshi, M. R. J. (2015). Improved model to test applications using smart services. Science International, 27(3), 2275-2280.

Allmendinger, G., \& Lombreglia, R. (2005). Four strategies for the age of smart services. Harvard Business Review, 83(10), 131-145.

Alti, A., Laborie, S., \& Roose, P. (2015). Cloud semantic-based dynamic multimodal platform for building mHealth context-aware services. In Proceedings of the 11th IEEE International Conference on Wireless and
Mobile Computing, Networking and Communications, Abu Dhabi, United Arab Emirates, October 19-21, 2015 (pp. 357-364).

Anthopoulos, L., \& Fitsilis, P. (2014). Exploring architectural and organizational features in smart cities. In Proceedings of the 16th International Conference on Advanced Communication Technology, Pyeong Chang, South Korea, February 16-19, 2014 (pp. 190-194).

Anthopoulos, L., Janssen, M., \& Weerakkody, V. (2016). Smart service portfolios: Do the cities follow standards? In Proceedings of the 25th International Conference Companion on World Wide Web. Montréal, Canada, April, 11-15, 2016 (pp. 357-362).

Anttiroiko, A.-V., Valkama, P., \& Bailey, S. J. (2014). Smart cities in the new service economy: Building platforms for smart services. $A I$ \& SOCIETY, 29(3), 323-334.

Baldoni, R., Mecella, M., \& Querzoni, L. (2010). Smart services for home automation. Managing concurrency and failures: New wine in old bottles? In Proceedings of the 5th International Conference on Pervasive Computing and Applications, Maribor, Slovenia, December 1-3, 2010.

Barile, S., \& Polese, F. (2010). Smart service systems and viable service systems: Applying systems theory to service science. Service Science, 2(1-2), 21-40.

Batubara, F. R. (2015). Balancing functionality, risk, and cost in smart service networks. In Proceedings of the ICSOFT Doctoral Consortium, Colmar, France, July 20-23, 2015 (pp. 7-14).

Bedogni, L., Bononi, L., Di Felice, M., D'Elia, A., Mock, R., Montori, F., ... Vergari, F. (2013). An interoperable architecture for Mobile smart services over the internet of energy. In Proceedings of the 14th IEEE International Symposium on 'A World of Wireless, Mobile and Multimedia Networks', Madrid, Spain, June 4-7, 2013 (pp. 298-303).

Berna-Martinez, J., Macia-Perez, F., Ramos-Morillo, H., \& GilartIglesias, V. (2006). Distributed robotic architecture based on smart services. In Proceedings of the IEEE International Conference on Industrial Informatics, Singapore, Singapore, August 16-18, 2006 (pp. 480-485).

Bianchi, M. (2015). Willingness to believe and betrayal aversion: The special role of Trust in art Exchanges. Journal of Cultural Economics, 39(2), 133-151. 
Böcker, M., Rodriguez-Ascaso, A., Huttenrauch, H., Schneider, M., Pluke, M., \& Zetterstrom, E. (2010). Identifying enablers for future e-services. In Proceedings of the 4th International ICST Conference on Pervasive Computing Technologies for Healthcare, Munich, Germany, March 22-25, 2010.

Brotman, R., Burleson, W., Forlizzi, J., Heywood, W., \& Lee, J. (2015). Building change: Constructive design of smart domestic environments for goal achievement. In Proceedings of the 33rd Annual ACM Conference on Human Factors in Computing Systems, Seoul, Republic of Korea, April 18-23, 2015 (pp. 3083-3092).

Buchanan, S., \& McMenemy, D. (2012). Digital service analysis and design: The role of process modelling. International Journal of Information Management, 32(3), 251-256.

Buettner, R. (2016). Innovative personality-based digital services. In Proceedings of the Pacific Asia Conference on Information Systems, Chiayi, Taiwan, June 27 - July 1, 2016 (paper 278).

Byun, J., \& Park, S. (2011). Development of a self-adapting intelligent system for building energy saving and context-aware smart services. IEEE Transactions on Consumer Electronics, 57(1), 90-98.

Calza, F., Gaeta, M., Loia, V., Orciuoli, F., Piciocchi, P., Rarità, L., Spohrer, J., \& Tommasetti, A. (2015). Fuzzy consensus model for governance in smart service systems. Procedia Manufacturing, 3, $3567-3574$

Cardozo, N., \& Clarke, S. (2015). Language design for developing smart adaptive services. In Proceedings of the 1st IEEE International Smart Cities Conference, Guadalajara, Mexico, October 25-28, 2015.

Cater-Steel, A., Zarnekow, R., \& Wulf, J. (2011). IT service management in the academic curriculum: Comparing an Australian and German experience. In Proceedings of the 15th Pacific Asia Conference on Information Systems, Brisbane, Australia, July 7-11, 2011 (Paper 33).

Cellary, W. (2013). Smart governance for smart industries. In Proceedings of the 7th International Conference on Theory and Practice of Electronic Governance Seoul, Republic of Korea, October 22-25, 2013 (pp. 91-93).

Chatterjee, P., \& Armentano, R. L. (2015). Internet of things for a smart and ubiquitous eHealth system. In Proceedings of the 7 th International Conference on Computational Intelligence and Communication Networks, Jabalpur, India, December 12-14, 2015 (pp. 903-907)

Chen, J., Yuan, L., \& Mingins, C. (2012). NeSD: Towards a new eservices development framework. In Proceedings of the 11th Wuhan International Conference on e-Business, Wuhan, China, May 26-27, 2012 (pp. 555-562).

Chu, Y.-Y., \& Lin, S.-W. (2011). Network ontology and dynamics analysis for collaborative innovation in digital services. In Proceedings of the Portland International Center of Management of Engineering and Technology, Portland, OR, USA, July 31 - August 4, 2011.

Ciortea, A., Boissier, O., Zimmermann, A., \& Florea, A. M. (2016). Responsive decentralized composition of service mashups for the internet of things. In Proceedings of the 6th International Conference on the Internet of Things, Stuttgart, Germany, November 07-09, 2016 (pp. 53-61).

Dawid, H., Decker, R., Hermann, T., Jahnke, H., Klat, W., König, R., \& Stummer, C. (2016). Management science in the era of smart consumer products: Challenges and research perspectives. Central European Journal of Operations Research, 25(1), 203-230.

De Oliveira, V. C., \& Silva, J. R. (2015). A service-oriented framework to the design of information system service. Journal of Service Science Research, 7(2), 55-96.

Delfanti, M., Esposito, G., Olivieri, V., \& Zaninelli, D. (2015). SCUOLA project: The 'hub of smart services' for cities and communities. In Proceedings of the 4th International Conference on Renewable Energy Research and Applications, Palermo, Italy, November 2225, 2015 (pp. 1502-1506).
Demirkan, H., Bess, C., Spohrer, J., Rayes, A., Allen, D., \& Moghaddam, Y. (2015). Innovations with smart service systems: Analytics, big data, cognitive assistance, and the internet of everything. Communications of the Association for Information Systems, 37(1), 733-752.

Domingues, J., Damaso, A., \& Rosa, N. (2010). Smart: Service model for integrating wireless sensor networks and the internet. In Proceedings of the 16th IEEE International Conference on Parallel and Distributed Systems, Shanghai, China, December 810, 2010 (pp. 365-372).

Fan, Z., Chen, Q., Kalogridis, G., Tan, S., \& Kaleshi, D. (2012). The power of data: Data analytics for M2M and smart grid. In Proceedings of the 3rd IEEE PES Innovative Smart Grid Technologies Europe, Berlin, Germany, October 14-17, 2012.

Fan, M., Sun, J., Zhou, B., \& Chen, M. (2016). The smart health initiative in China: The case of Wuhan, Hubei Province. Journal of Medical Systems, 40(3), 62.

Ferneley, E., Wetherill, M. \& Rezgui, Y. (2002). Toward the construction knowledge economy: The E-Cognos project. In Proceedings of the 10th European Conference on Information Systems, Gdańsk, Poland, June 6-8, 2002 (pp. 1508-1516).

Ferretti, S., \& D'Angelo, G. (2016). Smart shires: The revenge of Countrysides. In Proceedings of the 21st IEEE Symposium on Computers and Communication, Messina, Italy, June 27-30, 2016 (pp. 756-759).

Ferretti, S., D'Angelo, G., \& Ghini, V. (2016). Smart multihoming in smart shires: Mobility and communication Management for Smart Services in Countrysides. In Proceedings of the 21st IEEE Symposium on Computers and Communication, Messina, Italy, June 27-30, 2016 (pp. 970-975).

Fischbach, M. M., Puschmann, T. \& Alt, R. (2013). Enhancing Soa with service lifecycle management - towards a functional reference model. In Proceedings of the 21st European Conference on Information Systems, Utrecht, Netherlands, June 5-8, 2013 (Paper 170).

Gavrilova, T., \& Kokoulina, L. (2015). Smart services classification framework. In Proceedings of the Federated Conference on Computer Science and Information Systems, Lodz, Poland, September 13-16, 2015 (pp. 203-207).

Georgakopoulos, D., \& Jayaraman, P. P. (2016). Internet of things: From internet scale sensing to smart services. Computing, 98(10), 1041-1058.

Gerke, K., \& Tamm, G. (2009). Continuous quality improvement of IT processes based on reference models and process mining. In Proceedings of the Americas Conference on Information Systems, San Francisco, USA, August 6-9, 2009 (Paper 786).

Geum, Y., Jeon, H., \& Lee, H. (2016). Developing new smart services using integrated morphological analysis: Integration of the market-pull and technology-push approach. Service Business, 10(3), 531-555.

Gillig, H., \& Sailer, K. (2012). User involvement in the innovation process: Development of a framework for e-services. In In Proceedings of the 18th International Conference on Engineering, Technology and Innovation, Munich, Germany, June 18-20 (p. 2010).

Gretzel, U., Sigala, M., Xiang, Z., \& Koo, C. (2015). Smart tourism: Foundations and developments. Electronic Markets, 25(3), 179-188.

Hamdan, D., Aktouf, O.-E.-K., Parissis, I., Hijazi, A., Sarkis, M., \& El Hassan, B. (2012). SMART service for fault diagnosis in wireless sensor networks. In Proceedings of the 6th International Conference on Next Generation Mobile Applications, Services and Technologies, Paris, France, September 12-14, 2012 (pp. 211-216).

He, J., Zhang, Y., Huang, G., \& Cao, J. (2012). A smart web service based on the context of things. ACM Transactions on Internet Technology, 11(3), 1-23.

Holgado, M., \& Macchi, M. (2014). Exploring the role of e-maintenance for value creation in service provision. In Proceedings of the 
International ICE Conference on Engineering, Technology and Innovation, Bergamo, Italy, June 23-25, 2014 (pp. 174-183).

Hong, L., She, Z., Ye, J., \& Chen, X. (2014). An exploration research of establishing E-service dimensions model by building up service quality indexes based on process interaction. In Proceedings of the 11th International Conference on Service Systems and Service Management, Beijing, China, June 25-27, 2014.

Jerald, A. V., Rabara, S. A., \& Bai, D. P. (2016). Secure IoT architecture for integrated smart services environment. In Proceedings of the $3 \mathrm{rd}$ International Conference on Computing for Sustainable Global Development, New Delhi, India, March 16-18, 2016 (pp. 800-805).

Kamp, B., Ochoa, A., \& Diaz, J. (2016). Smart servitization within the context of industrial user-supplier relationships: Contingencies according to a machine tool manufacturer. International Journal on Interactive Design and Manufacturing 2016.

Kennedy, D., \& Keskin, T. (2016). A pricing model for the internet of things enabled smart service systems. In Proceedings of the 49th Hawaii International Conference on System Sciences, Kauai, HI, USA, January 5-8, 2016 (pp. 1782-1789).

Keskin, T., \& Kennedy, D. (2015). Strategies in smart service systems enabled multi-sided markets: Business models for the internet of things. In Proceedings of the 48th Hawaii International Conference on System Sciences, Kauai, Hawaii, USA, January 5-8, 2015 (pp. 1443-1452).

Kim, M. J., Lee, J. H., Wang, X., \& Kim, J. T. (2015). Health smart home services incorporating a MAR-based energy consumption awareness system. Journal of Intelligent and Robotic Systems, 79(3), 523-535.

Knote, R., \& Blohm, I. (2016). It's not about having ideas - It's about making ideas happen! Fostering exploratory innovation with Intrapreneur accelerator. In Proceedings of the 24th European Conference on Information Systems, Instanbul, Turkey, June 1215, 2016 (Paper 59).

Kölmel, B., \& Bulander, R. (2015). Sustainability and competitiveness through digital product-service-systems. In Proceedings of the eChallenges e-2015 Conference, Vilnius, Lithuania, November 2526, 2015.

Korzun, D. G., Borodin, A. V., Timofeev, I. A., Paramonov, I. V., \& Balandin, S. I. (2015). Digital assistance Services for Emergency Situations in personalized Mobile healthcare: Smart space based approach. In Proceedings of the International Conference on Biomedical Engineering and Computational Technologies, Novosibirsk, Russia, October 28 and 30, 2015 (pp. 62-67).

Koukal, A., Gleue, C., \& Breitner, M. H. (2014). Enhancing literature review methods - Evaluation of a literature search approach based on latent semantic indexing. In Proceedings of the 35th International Conference on Information Systems, Auckland, New Zealand, December 14-17, 2014.

Kryvinska, N., Strauss, C., Auer, L., \& Zinterhof, P. (2008). Conceptual framework for services creation/development environment in telecom domain. In Proceedings of the 10th International Conference on Information Integration and Web-based Applications \& Services, Linz, Austria, November 24-26, 2008 (pp. 324-331).

Kuebel, H., \& Zarnekow, R. (2015). Exploring platform adoption in the smart home case. In Proceedings of the 36th International Conference on Information Systems, Fort Worth, TX, USA, December 13-16, 2015.

Kwak, J.-Y., Kim, S.-T., Lee, K. H., \& Yang, S. (2014). Service-oriented networking platform on smart devices. IET Communications, 9(3), 429-439.

Kynsilehto, M., \& Olsson, T. (2011). Intelligent ambient technologyfriend or foe? In Proceedings of the 15th International Academic MindTrek Conference, Tampere, Finland, September 28-30, 2011 (pp. 99-106)

Kynsilehto, M., \& Olsson, T. (2012). Checkpoints, hotspots and standalones - Placing smart services over time and place. In
Proceedings of the 7th Nordic Conference on Human-Computer Interaction: Making Sense Through Design, Copenhagen, Denmark, October 14-17, 2012 (pp. 209-218).

Lê Tuán, A., Mau Quoc, H. N., Serrano, M., Hauswirth, M., Soldatos, J., Papaioannou, T., \& Aberer, K. (2012). Global sensor modeling and constrained application methods enabling cloud-based open space smart services. In Proceedings of the 9th International Conference on Ubiquitous Intelligence and Computing and 9th International Conference on Autonomic and Trusted Computing, Fukuoka, Japan, September 4-7, 2012 (pp. 196-203).

Lebedev, N., Timofeev, I., \& Zavialova, I. (2016). Design and implementation of the first aid assistance service based on smart-M3 platform. In Proceedings of the 18th Conference of Open Innovations Association and Seminar on Information Security and Protection of Information Technology, St. Petersburg, Russia, April 18-22, 2016 (pp. 174-180).

Lee, B.-H., Lim, S.-H., \& Kim, J.-H. (2010). Scalable real-time monitoring system for ubiquitous smart space. Information Processing Letters, 110(8-9), 294-299.

Lee, J. Y., Kim, M. K., La, H. J., \& Kim, S. D. (2012). A software framework for enabling smart services. In Proceedings of the 5th IEEE International Conference on Service-Oriented Computing and Applications, Taipei, Taiwan, December 17-19, 2012 (pp. 55-62).

Lee, N., Lee, H., Lee, H., \& Ryu, W. (2015). Implementation of smart home service over web of object architecture. In Proceedings of the 6th International Conference on Information and Communication Technology Convergence, Jeju Island, South Korea, October 28-30, 2015 (pp. 1215-1219).

Lee, H., Seol, H., Min, H., \& Geum, Y. (2016). The identification of new service opportunities: A case-based morphological analysis. Service Business, 11(1), 191-206.

Lesjak, C., Ruprechter, T., Bock, H., Haid, J., \& Brenner, E. (2014). ESTADO - Enabling smart services for industrial equipment through a secured, transparent and ad-hoc data transmission online. In Proceedings of the 9th International Conference for Internet Technology and Secured Transactions, London, United Kingdom, December 8-10, 2014 (pp. 171-177).

Lesjak, C., Hein, D., Hofmann, M., Maritsch, M., Aldrian, A., Priller, P., ... Pregartner, G. (2015). Securing smart maintenance services: Hardware-security and TLS for MQTT. In Proceedings of the 13th International Conference on Industrial Informatics, Cambridge, United Kingdom, July 22-24, 2015 (pp. 1243-1250).

Li, Y., Wan, Z., Huang, J., Chen, J., Huang, Z., \& Zhong, N. (2015). A smart hospital information system for mental disorders. In Proceedings of the 2015 IEEE/WIC/ACM international conference on web intelligence and intelligent agent technology, Singapore, Singapore, December 6-9, 2015 (pp. 321-324).

Ma, X., Qian, K., Dai, X., Fang, F., \& Xing, Y. (2010). Framework design for distributed service robotic systems. In Proceedings of the 5th IEEE Conference on Industrial Electronics and Applications, Taichung, Taiwan, June 15-17, 2010 (pp. 234-239).

Maleshkova, M., Philipp, P., Sure-Vetter, Y., \& Studer, R. (2016). Smart web services (SmartWS) - The future of services on the web. The IPSI BgD Transactions on Advanced Research, 12(1), 15-26.

Martin, N., Gregor, S., \& Hart, D. (2004). Using a common architecture in Australian e-government - the case of smart service Queensland. In Proceedings of the 6th International Conference on Electronic Commerce, Delft, Netherlands, October 25-27, 2004 (pp. 516-525).

Massink, M., Harrison, M., \& Latella, D. (2010). Scalable analysis of collective behaviour in smart service systems. In Proceedings of the ACM Symposium on Applied Computing, Sierre, Switzerland, March 22-26, 2010 (pp. 1173-1180).

Mathes, M., Stoidner, C., Schwarzkopf, R., Heinzl, S., Dörnemann, T., Dohmann, H., \& Freisleben, B. (2009). Time-constrained services: A framework for using real-time web Services in Industrial 
Automation. Service Oriented Computing and Applications, 3(4), 239-262.

Mecella, M., \& Pernici, B. (2001). Designing wrapper components for eServices in Integrating Heterogeneous Systems. The VLDB Journal, 10(1), 2-15.

Mihaylov, M., Mihovska, A., Kyriazakos, S., \& Prasad, R. (2015). Interoperable eHealth platform for personalized smart services. In Proceedings of the IEEE International Conference on Communication Workshop, London, UK, June 8-12, 2015 (pp. 240-245).

Mihovska, A., Kyriazakos, S., Prasad, R., Pejanovic-Djurisic, M., \& Poulkov, V. (2015). Integration of wireless and data technologies for personalized smart applications. In Proceedings of the 14th Wireless Telecommunications Symposium (WTS), New York City, NY, USA, April 15-17, 2015 (pp. 304-311).

Mo, T., Li, W., Chu, W., \& Wu, Z. (2010). CABS ${ }^{3}$ : Context-awareness based smart service system. In Proceedings of the 6th International Conference on Wireless Communications Networking and Mobile Computing, Chengdu City, China, September 23-25, 2010 (pp. 1834-1837).

Moawad, A., Hartmann, T., Fouquet, F., Klein, J., \& Le Traon, Y. (2015). Adaptive blurring of sensor data to balance privacy and utility for ubiquitous services. In Proceedings of the 30th Annual ACM Symposium on Applied Computing, Salamanca, Spain, April 1317, 2015 (pp. 2271-2278).

Mukudu, N., Ventura, N., Mwangama, J., Elmangoush, A., Steinke, R., \& Magedanz, T. (2016). Prototyping smart city applications over large scale M2M testbed. In Proceedings of the 2016 IST-Africa week conference, Durban, South Africa, May 11-13, 2016.

Nakajima, H., Shiga, T., \& Hata, Y. (2012). Systems health care: Coevolutionary integration of smart devices and smart services. In Proceedings of the Annual SRII Global Conference, San Jose, CA, USA, July 24-27, 2012 (pp. 231-236).

Niemann, M., Appel, M., Repp, N., \& Steinmetz, R. (2009). Towards a consistent service lifecycle model in service governance. In Proceedings of the Americas Conference on Information Systems, San Francisco, USA, August, 6-9, 2009 (Paper 109).

Oh, J. S., Park, J. S., \& Kwon, J. R. (2010). Ubiquitous infrastructure and smart service on City gas environments in Korea. In Proceedings of the 5th International Conference on Future Information Technology, Busan, South Korea, May 21-23, 2010.

Oslislo, L. J., Talevski, A., \& Karduck, A. P. (2011). SMART CAMP: Benefits of media and smart service convergence. In Proceedings of the 25th IEEE Workshops of International Conference on Advanced Information Networking and Applications, Biopolis, Singapore, March 22-25, 2011 (pp. 763-768).

Paluch, S., \& Wünderlich, N. V. (2016). Contrasting risk perceptions of technology-based service innovations in inter-organizational settings. Journal of Business Research, 69(7), 2424-2431.

Pao, S.-Y., Reben, A. J., \& Rayes, A. (2011). MoSS: Mobile smart services for ubiquitous network management. In Proceedings of the International Conference on Collaboration Technologies and Systems, Philadelphia, PA, USA, May 23-27, 2011 (pp. 48-52).

Perera, C., Zaslavsky, A., Christen, P., \& Georgakopoulos, D. (2014). Sensing as a service model for smart cities supported by internet of things. Transactions on Emerging Telecommunications Technologies, 25(1), 81-93.

Pistofidis, P., \& Emmanouilidis, C. (2012). Developing advanced context aware tools for mobile maintenance. In Proceedings of the 2nd IFAC Workshop on Advanced Maintenance Engineering, Services and Technology, Sevilla, Spain, November 22-23, 2012 (pp. 133-138).

Priller, P., Aldrian, A., \& Ebner, T. (2014). Case study: From legacy to connectivity: Migrating industrial devices into the world of smart services. In Proceedings of the 19th IEEE Emerging Technology and Factory Automation, Barcelona, Spain, September 16-19, 2014.
Ren, J., Ma, J., Huang, R., Jin, Q., \& Chen, Z. (2014). A management system for cyber individuals and heterogeneous data. In Proceedings of the 11th IEEE International Conference on Ubiquitous Intelligence and Computing and 11th IEEE International Conference on Autonomic and Trusted Computing and 14th IEEE International Conference on Scalable Computing and Communications and Its Associated Workshops, Bali, Indonesia, December 9-12, 2014 (pp. 88-95).

Roduner, C., \& Langheinrich, M. (2010). BIT - A framework and architecture for providing digital services for physical products. In Proceedings of the Internet of Things Conference, Tokyo, Japan, November 29 - December 1, 2010, (pp. 170-177).

Sakakibara, S., Saiki, S., Nakamura, M., \& Matsumoto, S. (2016). Indoor environment sensing service in smart City using autonomous sensor box. In Proceedings of the 15th IEEE/ACIS International Conference on Computer and Information Science, Okayama, Japan, June 26-29, 2016.

Seeliger, R., Krauss, C., Wilson, A., Zwicklbauer, M., \& Arbanowski, S. (2015). Towards personalized Smart City guide services in future internet environments. In Proceedings of the 24th International Conference on World Wide Web, Florence, Italy, May 18-22, 2015 (pp. 563-568).

Singhai, A. J., \& Faizan, D. (2016). Transition of Indian ICT processes to smart E-services-way ahead. In Proceedings of the 5th International Conference on Advances in Computing, Communications and Informatics, Jaipur, India, September 21-24, 2016 (pp. 1479-1486).

Smirnov, A. V., Kashevnik, A. M., Ponomarev, A. V., \& Savosin, S. V. (2015). Ontology-based organization of interactions between services in the smart space for hybrid system control. Scientific and Technical Information Processing, 42(5), 367-374.

Smith, G., Ofe, H. A., \& Sandberg, J. (2016). Digital service innovation from open data: Exploring the value proposition of an open data marketplace. In Proceedings of the 49th Hawaii International Conference on System Sciences, Kauai, HI, USA, January 5-8, 2016 (pp. 1277-1286).

Sohn, I., \& Gwak, D. (2016). Single-RF MIMO-OFDM system with beam switching antenna. Journal on Wireless Communications and Networking, 2016(37).

Son, J.-Y., Park, J.-H., Moon, K.-D., \& Lee, Y.-H. (2011). Resourceaware smart home management system by constructing resource relation graph. IEEE Transactions on Consumer Electronics, 57(3), 1112-1119.

Spottke, B., Eck, A., \& Wulf, J. (2016). A socio-technical approach to study consumer-centric information systems. In In Proceedings of the 37th International Conference on Information Systems, Dublin, Ireland, December 11-14 (p. 2016).

Strüker, J., \& Kerschbaum, F. (2012). From a barrier to a bridge: Dataprivacy in deregulated smart grids. In In Proceedings of the 33rd International Conference on Information Systems, Orlando, FL, USA, December 16-19 (p. 2012).

Tantatsanawong, P., Kawtrakul, A., \& Lertwipatrakul, W. (2011). Enabling future education with smart services. In Proceedings of the Annual SRII Global Conference, San Jose, CA, USA, March 29 - April 2, 2011 (pp. 550-556).

Theocharis, S. A., \& Tsihrintzis, G. A. (2013). Personalization as a means to improve e-services. In Proceedings of the 2 nd International Conference on Computer, Information and Telecommunication Systems, Piraeus-Athens, Greece, May 7-8, 2013.

Tianyong, W., Xu Zhengliang, X., \& Gel, G. (2006). Development and strategy of knowledge management for e-services. In Proceedings of the International Conference on Service Systems and Service Management, Troyes, France, October 25-27, 2006.

Tien, J. M. (2012). The next industrial revolution: Integrated services and goods. Journal of Systems Science and Systems Engineering, 21(3), 257-296. 
Vom Brocke, J., Simons, A., Niehaves, B., Reimer, K., Plattfaut, R., \& Cleven, A. (2009). Reconstructing the Giant: On the importance of rigour in documenting the literature search process. In Proceedings of the 17th European Conference on Information Systems, Verona, Italy, June 8-10, 2009 (pp. 2206-2217).

Wang, C., Akella, R., Ramachandran, S., \& Hinnant, D. (2011). Knowledge extraction and reuse within "smart" service centers. In Proceedings of the Annual SRII Global Conference, San Jose, CA, USA, March 29 - April 2, 2011 (pp. 163-176).

Wang, Y., Taher, Y., \& van den Heuvel, W.-J. (2012). Towards smart service networks: An interdisciplinary service assessment metrics. In Proceedings of the 16th IEEE International Enterprise Distributed Object Computing Conference Workshops, Beijing, China, September 10-14, 2012 (pp. 94-103).

Webster, J., \& Watson, R. T. (2002). Analyzing the past to prepare for the future: Writing a literature review. Management Information Systems Quarterly, 26(2), xiii-xxiii.

Weijie, C., Tong, M., Jie, C., Yuan, W., Jingmin, X., Weiping, L., \& Huiping, L. (2012). A context-aware services development model. In Proceedings of the International Joint Conference on Service Sciences, Shanghai, China, May 24-26, 2012 (pp. 194-199).

Westwood, J. A., \& Cazier, J. A. (2016). Work-life optimization: Using big data and analytics to facilitate work-life balance. In Proceedings of the 49th Hawaii International Conference on System Sciences, Kauai, HI, USA, January 5-8, 2016 (pp. 1701-1709).

Wiesner, S., Freitag, M., Westphal, I., \& Thoben, K.-D. (2015). Interactions between service and product lifecycle management. In Proceedings of the 7th Industrial Product-Service Systems Conference, saint-Etienne, France, May 21-22, 2015 (pp. 36-41).

Williams, K., Chatterjee, S., \& Rossi, M. (2008). Design of Emerging Digital Services: A taxonomy. European Journal of Information Systems, 17(5), 505-517.

Wünderlich, N. V., von Wangenheim, F., \& Bitner, M. J. (2012). High tech and high touch: A framework for understanding user attitudes and behaviors related to smart interactive services. Journal of Service Research, 16(1), 3-20.

Wünderlich, N. V., Heinonen, K., Ostrom, A. L., Patricio, L., Sousa, R., Voss, C., \& Lemmink, J. G. (2015). 'Futurizing' smart service: Implications for service researchers and managers. Journal of Services Marketing, 29(6/7), 442-447.

Yachir, A., Tari, K., Amirat, Y., Chibani, A., \& Badache, N. (2009). QoS based framework for ubiquitous robotic services composition. In Proceedings of the IEEE/RSJ International Conference on Intelligent Robots and Systems, St. Louis, MO, USA, October 1015, 2009 (pp. 2019-2026).

Yang, Q. Z., Miao, C. Y., \& Shen, Z. Q. (2015). Digital services innovation for aging-in-place. In Proceedings of the 22nd International Conference on Industrial Engineering and Engineering Management, Singapore, Singapore, December 6-9, 2015 (pp. 569-573).

Yong, M., \& Hui-ying, C. (2013). Study on the value promotion and development strategy of smart tourism. In Proceedings of the 12th Wuhan International Conference on e-Business, Wuhan, China, May 25-26, 2013 (paper 45).

Yu, C.-C. (2004). A web-based consumer-oriented intelligent decision support system for personalized e-services. In Proceedings of the 6th International Conference on Electronic Commerce, Delft, Netherlands, October 25-27, 2004 (pp. 429-437).

Zhang, J., \& Qi, B. (2011). Studies on interactive service platform for smart grid. In Proceedings of the IEEE PES Innovative Smart Grid Technologies Asia, Perth, Australia, November, 13-16, 2011 (pp. 213-216).

Zo, H. (2003). Personalization vs. customization: Which is more effective in E-services? In Proceedings of the 9th Americas Conference on Information Systems, Tempa, FL, USA, August 4-6, 2003 (Paper 32). 